\title{
过渡金属杂小环的扩环反应研究进展
}

\author{
卓庆德王铜道周小茜张弘* \\ ( ${ }^{a}$ 厦门大学化学化工学院 厦门 361005)
}

\begin{abstract}
摘要 过渡金属杂环化合物特别是过渡金属杂小环化合物(成环原子数小于 6)在金属有机化学和配位化学领域中具有 重要的地位，它们是许多过渡金属催化反应包括烯烃复分解反应、炔烃聚合反应的中间体. 通常过渡金属杂小环化合 物具有较大的环张力, 因此极易与不饱和化合物反应生成环张力较小的扩环产物. 针对过渡金属杂小环化学研究现状, 综述了几类典型的过渡金属杂三、四、五元环的扩环反应.
\end{abstract}

关键词 过渡金属; 杂环化合物; 扩环反应

\section{Progresses of Ring Expansion Reaction of Small Transitional Metallacyclic Compounds}

\author{
Zhuo, Qingde Wang, Tongdao Zhou, Xiaoxi Zhang, Hong* \\ (Department of Chemistry, College of Chemistry and Chemical Engineering, Xiamen University, Xiamen 361005)
}

\begin{abstract}
Metallacycles, especially those small rings, play an important role in the field of organometallic and coordination chemistry. They are considered as reactive intermediates in metal promoted or catalyzed reactions including olefin metathesis reactions and alkyne polymerization reactions. Due to the high ring strain, small metallacycles can easily react with unsaturated compounds to produce ring expansion products with lower ring strain. To further understand the importance of small metallacycle intermediates in the catalytic reactions and synthesis methodology, the ring expansion reactions of several typical three-, four- and five-membered metallacycles is summarize.
\end{abstract}

Keywords transition metal; heterocyclic compounds; ring-expansion reaction

过渡金属杂环化合物，特别是过渡金属杂小环，在 金属有机化学和配位化学领域中具有重要的地位 ${ }^{[1]}$, 是 许多过渡金属催化反应，包括烯烃复分解反应 ${ }^{[2]}$ 、炔烃 聚合反应 ${ }^{[3]}$ 等重要有机合成反应的关键中间体.

由于过渡金属杂小环化合物的环张力大, 因而较难 进行这类化合物的分离和表征. 通常可通过配体取代反 应、开环反应和扩环反应 3 种方式缓解和释放该类化合 物的环张力. 其中, 最常见的方式是与不饱和化合物发 生扩环反应. 过渡金属杂单环化合物的扩环反应一般是 不饱和化合物对金属一碳键的直接插入, 而过渡金属杂 稠环化合物的扩环反应则常伴随有分子骨架的重排.

虽然过去已有多篇文章综述了过渡金属杂小环化 合物的反应性 ${ }^{[1]}$, 但是目前尚无针对其扩环反应的总结. 基于过渡金属杂小环化合物的扩环反应在过渡金属催
化反应及有机合成方法学研究中的重要性, 本文综述了 几类典型的过渡金属杂三、四、五元环的扩环反应，并 对各类型过渡金属杂小环扩环反应的特点进行总结. 由 于过渡金属杂三、四、五元环种类繁多，本文仅选择了 几类最常见且在催化及有机合成反应中具有重要应用 的过渡金属杂三、四、五元环化合物进行总结(主要结 构如 Chart 1 所示), 这些化合物中主环上只含 1 个过渡 金属原子, 个别还含 1 个主族杂原子.

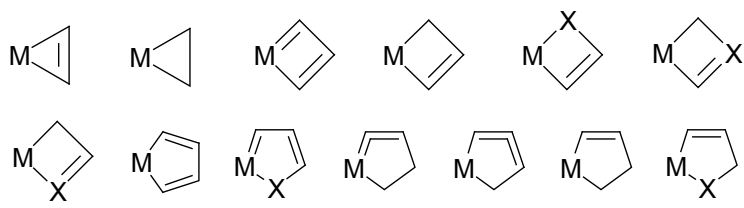

Chart 1

\footnotetext{
*E-mail: zh@xmu.edu.cn

Received March 24, 2014; revised April 21, 2014; published online May 5, 2014.

Project supported by the National Natural Science Foundation of China (No. 21272193) and the Natural Science Foundation of Fujian Province (No. 2011J05031).

国家自然科学基金(No. 21272193)和福建省自然科学基金(No. 2011J05031)资助项目.
} 


\section{1 过渡金属杂三元环化合物的扩环反应}

Dewer-Chatt-Duncanson 模型可以定性地解释烯烃 和炔烃等不饱和配体与过渡金属的相互作用 ${ }^{[4]}$. 该模型 的核心是两种不同的电子效应，包括配体成键轨道上的 $\pi$-电子对金属未占轨道的给电子效应和金属已占轨道 上的 $\mathrm{d}$-电子对配体反键轨道的反馈效应 ${ }^{[5]}$. 两种电子效 应的相对强弱决定了金属与配体的成键方式. 其中两种 成键极限形式包括配体的给电子效应很强而金属的反 馈效应很弱时形成 “金属 $\pi$-配合物”, 以及配体的给电 子效应很弱而金属的反馈效应很强时形成 “金属杂三元 环化合物”。烯烃和炔烃与过渡金属的成键形式通常界 于这两种极限式之间，可用共振式来表示(Scheme 1). 共振结构中两种极限式的贡献可通过键长、键角以及反 应性进行判断. 通常 “金属 $\pi$-配合物” 易与亲核试剂反 应，而 “金属杂三元环化合物” 易与不饱和底物发生插 入反应 ${ }^{[6]}$.
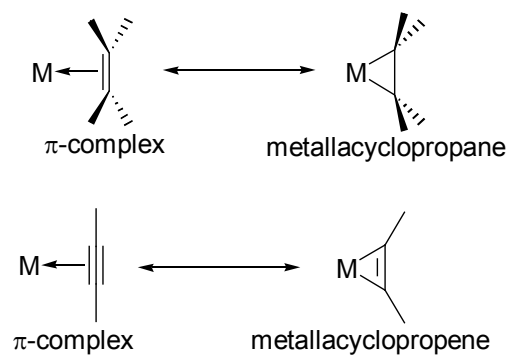

Scheme 1

以下简要介绍金属杂环丙烯和金属杂环丙烷的扩 环反应。

\section{1 过渡金属杂环丙烯的扩环反应}

1975 年, Wakatsuki 等 ${ }^{[7]}$ 研究了钴杂环丙烯与异腈的 反应. 异腈的投料比不同可分别生成钴杂四元环或钴杂 五元环化合物. 如 Scheme 2 所示, 钴杂环丙烯 1 与一分 子苯基异腈反应生成钴杂环丁烯 2 , 而与两分子苯基异 腈反应生成烯基与金属中心配位的钴杂环戊烯 $\mathbf{3}$,与三 分子苯基异腈反应则得到稳定的钴杂环戊烯 4 .

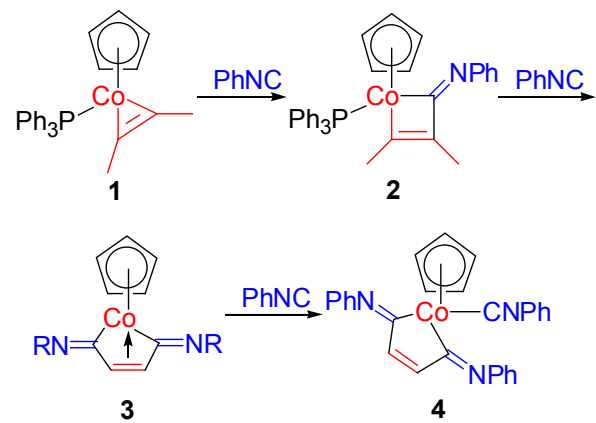

Scheme 2
1986 年, Buchwald 等 ${ }^{[8]}$ 系统研究了锆杂环丙烯的反 应性，锆杂环丙烯 5 能与不饱和化合物腈、酮、醛、烯 烃和炔烃等发生扩环反应，分别生成锆杂五元环化合物 6 11 (Scheme 3). 此外, 他们 ${ }^{[9]}$ 还研究了锆的苯炔配合 物的反应性，其与不饱和化合物的反应与锆杂环丙烯相 应反应结果类似.

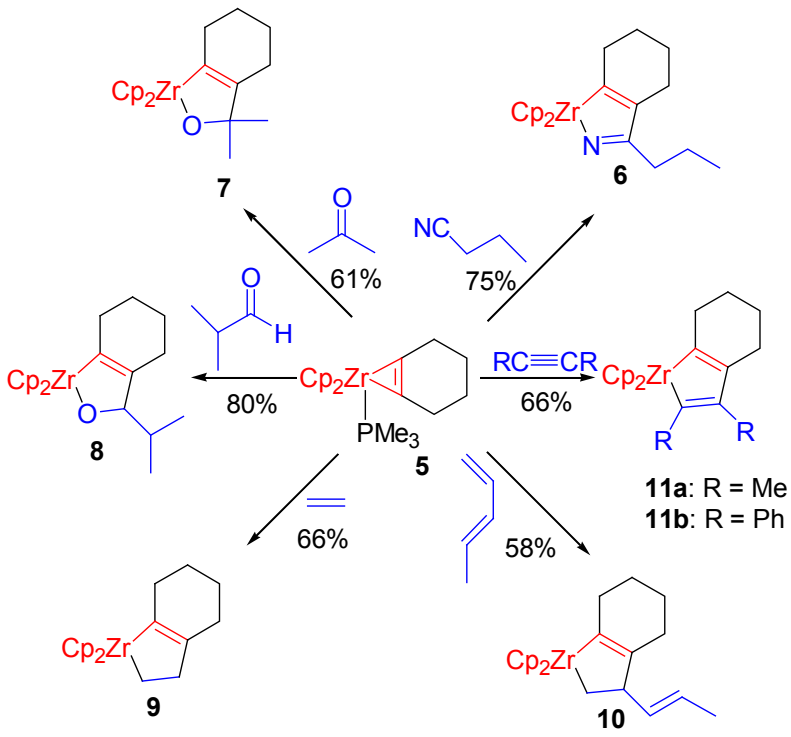

Scheme 3

1989 年, Hillhouse 等 ${ }^{[10]}$ 研究了第四族金属杂环丙烯 12 与一氧化二氮的反应，反应生成一氧化二氮插入的 扩环产物化合物 13, 化合物 13 不稳定，室温下易离去 一分子 $\mathrm{N}_{2}$, 形成四元环化合物 14 (Scheme 4).

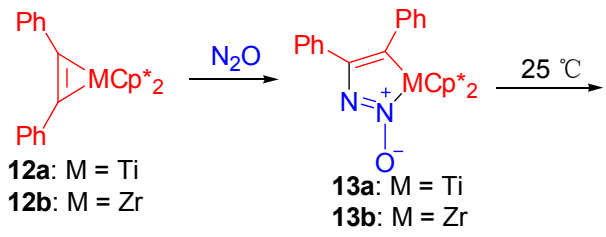

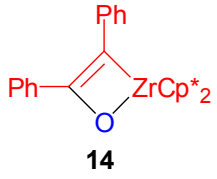

Scheme 4

1996 年, Teuben 等 ${ }^{[11]}$ 合成了第一例钒的苯炔配合 物 16, 研究结果表明该化合物应描述为 “钒杂环丙烯”. 16 与炔烃、烯烃都能发生扩环反应生成苯并金属杂五元 环化合物(Scheme 5), 这一反应性研究结果证明其结构 应为金属杂环丙烯.

2009 年, Rosenthal 等 ${ }^{[12]}$ 研究了第四族金属杂环丙 烯催化乙烯聚合反应的机理. 研究发现, 常温下铪杂环 丁烯 20 在乙烯气氛的甲苯溶液中与乙烯反应生成扩环 


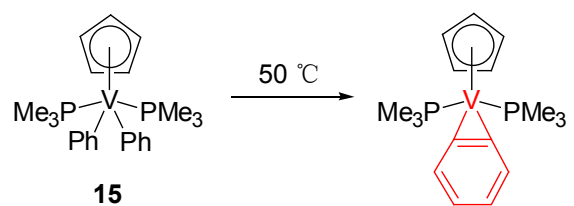

16

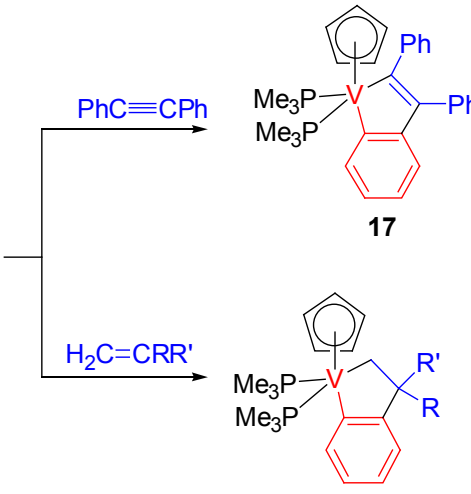

18a: $R, R^{\prime}=H$

18b: $R=H, R^{\prime}=M e$

18c: $R, R^{\prime}=M e$

Scheme 5

产物铪杂环戌烯化合物 21. 化合物 21 不稳定, 只能溶 液条件下存在, 并且脱离乙烯气氛后, 21 又会重新生成 20 (Scheme 6). 锆杂环丙烯在低温下也能发生类似的反 应 $^{[13]}$.

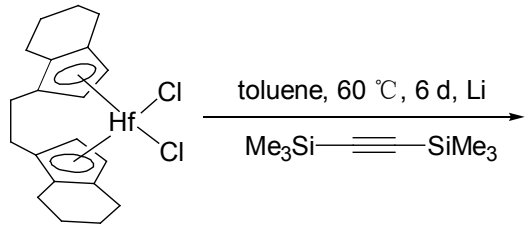

19

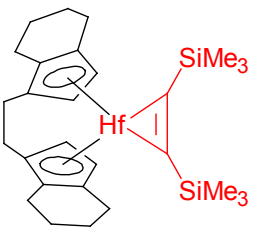

20
$\mathrm{H}_{2} \mathrm{C}=\mathrm{CH}_{2}$, toluene, r.t.

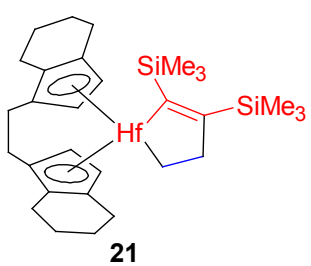

Scheme 6

2010 年, $X i$ 等 ${ }^{[14]}$ 系统研究了锆杂环丙烯化合物 22 的反应性. 化合物 22 能与不饱和化合物酮、碳二亚胺和 炔发生扩环反应分别生成锆杂五元环化合物 23, 24 和 25. 另外, 22 也能与小位阻腈反应, 先发生骨架重排, 最终得到七元环扩环产物 26 (Scheme 7).

\section{2 过渡金属杂环丙烷的扩环反应}

1999 年, Piers 等 ${ }^{[15]}$ 通过锆金属配合物 27 在还原条 件下与 $\mathrm{PMe}_{3}$ 及乙烯反应合成了锆杂环丙烷 28 , 并研究 了其反应性. 化合物 28 与过量的乙烯能发生扩环反应

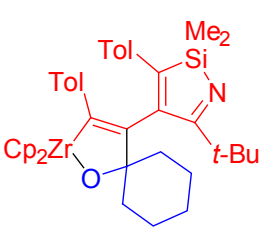

23: $72 \%$

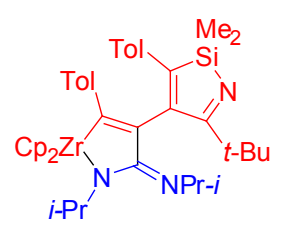

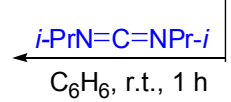

24: $86 \%$

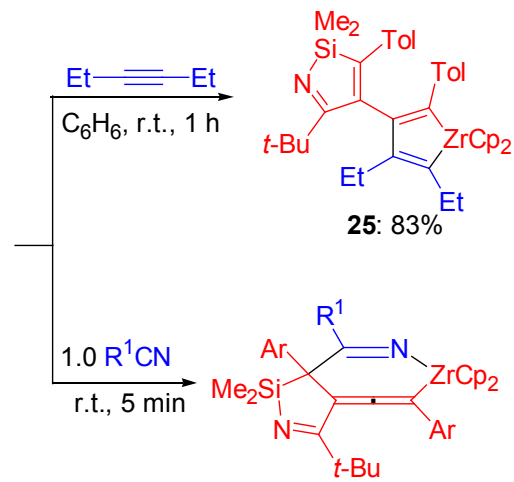

26a: $\mathrm{Ar}=\mathrm{Tol}, \mathrm{R}^{1}=\mathrm{Ph}, 86 \%$

26b: $\mathrm{Ar}=\mathrm{Tol}, \mathrm{R}^{1}=4-\mathrm{ClC}_{6} \mathrm{H}_{4}, 91 \%$

26c: $\mathrm{Ar}=\mathrm{Ph}, \mathrm{R}^{1}=2$-pyridyl, $73 \%$

26d: $\mathrm{Ar}=\mathrm{Tol}, \mathrm{R}^{1}=2$-pyrazinyl, $62 \%$

26e: $\mathrm{Ar}=\mathrm{Ph}, \mathrm{R}^{1}=4$-biphenyl, $68 \%$

26f: $\mathrm{Ar}=\mathrm{Ph}, \mathrm{R}^{1}=2$-thienyl, $93 \%$

\section{Scheme 7}

生成锆杂环戊烷 29 , 在过量 $\mathrm{PMe}_{3}$ 存在的条件下, 29 又 能重新生成 28 (Scheme 8).

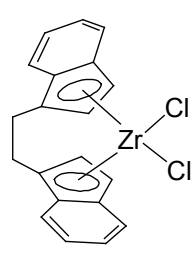

27
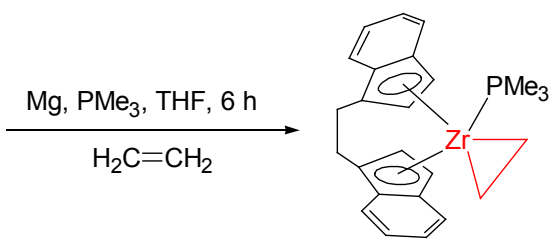

28

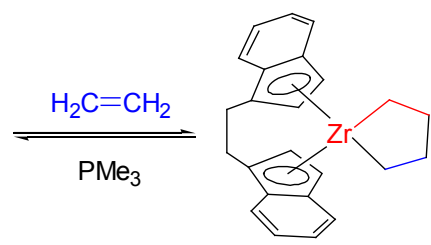

29

\section{Scheme 8}

2007 年, Nagashima 等 ${ }^{[6]}$ 报道了铂杂环丙烷 $\mathbf{3 0}$ 与异 腈的插入反应. 铂杂环丙烷 30 具有明显的金属杂环丙 
烷性质, 可以与两分子异腈反应生成铂杂环戊烷化合物 31 (Eq. 1). 这是金属杂环丙烷通过异腈插入扩环形成金 属杂环戊烷的首例报道.

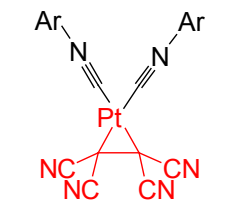

30

$\mathrm{Ar}=2,6-\mathrm{Me}_{2} \mathrm{C}_{6} \mathrm{H}_{3}$

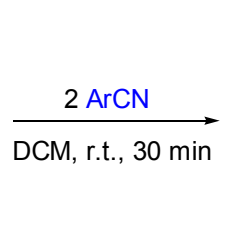

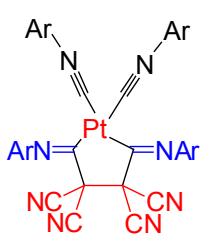

31

\section{2 过渡金属杂四元环化合物的扩环反应}

\section{1 过渡金属杂环丁二烯的扩环反应}

作为炔烃复分解反应的中间体, 金属杂环丁二烯 (Scheme 9)一直受到广泛关注, 对其扩环反应的深入研 究有利于探索炔烃复分解反应过程中催化剂的毒化机 理 ${ }^{[16]}$.

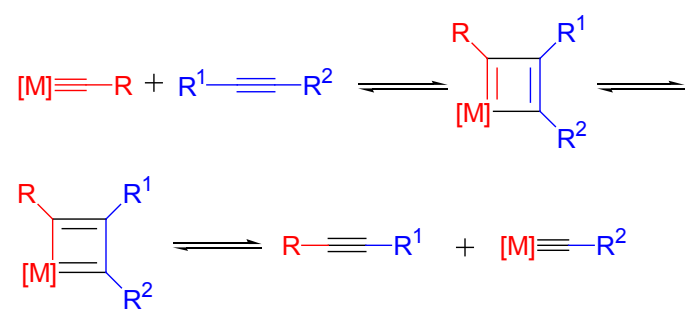

\section{Scheme 9}

1991 年, Berke 等 ${ }^{[17]}$ 通过铼羰基配合物 $(C O)_{5} \operatorname{Re}\left(\eta^{1}\right.$ $\mathrm{C}_{3} \mathrm{Ph}_{3}$ )环丙烯基配体的开环插入反应合成了具有电子离 域结构的锞杂环丁烯化合物 32, 并研究了其反应性. 化 合物 32 在氧化剂 $\mathrm{Me}_{3} \mathrm{NO}$ 作用下发生氧原子对金属一碳 键的插入反应生成扩环产物锞杂呋喃化合物 33. 化合 物 33 继续与 $\mathrm{Me}_{3} \mathrm{NO}$ 作用脱去一分子 $\mathrm{CO}$ 生成 $\mathrm{Me}_{3} \mathrm{~N}$ 取 代产物 34, 34 在 $\mathrm{CO}$ 气氛下甲苯中回流又能转化成化合 物 $\mathbf{3 3}$ (Scheme 10).
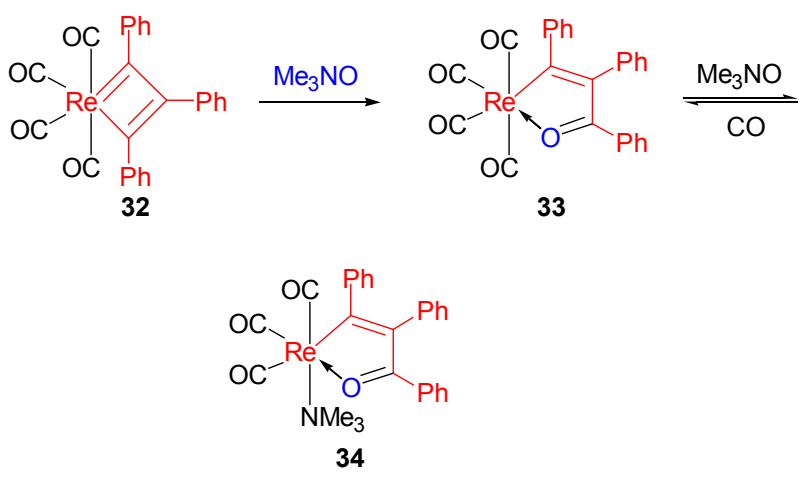

\section{Scheme 10}

1993 年, Wojcicki 等 ${ }^{[18]}$ 详细研究了具有 Fischer 卡宾
性质的锞杂环丁二烯 35 的反应性, 与锞杂环丁烯化合 物 32 类似, 铼杂环丁二烯 35 与氧化剂反应也得到氧插 入的扩环产物 36 和 37 (Eq. 2). 36 和 $\mathbf{3 7}$ 的比例与氧化剂 有关：当氧化剂是 $\left(\mathrm{NH}_{4}\right)_{2}\left[\mathrm{Ce}\left(\mathrm{NO}_{3}\right)_{6}\right], \mathrm{EtNO}_{2} / \mathrm{Et}_{3} \mathrm{~N}$ 或 DMSO 时，主要生成甲基取代碳一铼键插入产物 36; 当 氧化剂是 $\mathrm{Me}_{3} \mathrm{NO}$ 时, 主要生成烷氧基取代碳-锞键插入 产物 37.

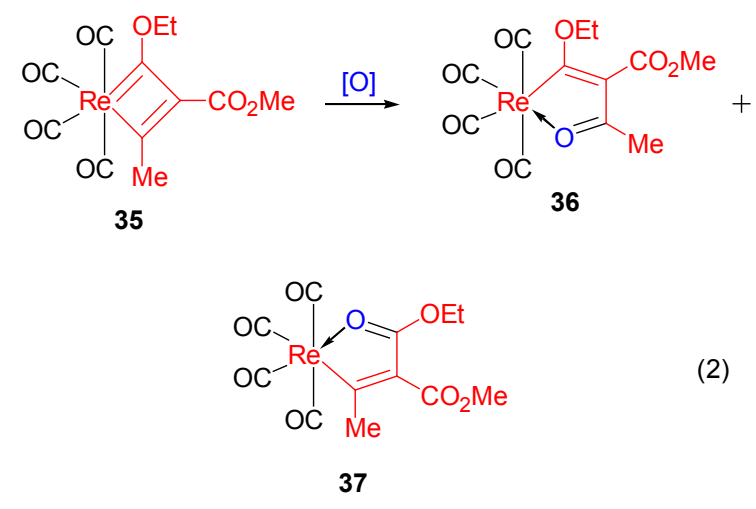

$[\mathrm{O}]=\left(\mathrm{NH}_{4}\right)_{2}\left[\mathrm{Ce}\left(\mathrm{NO}_{3}\right)_{6}\right], \mathrm{EtNO}_{2} / \mathrm{Et}_{3} \mathrm{~N}, \mathrm{DMSO}, \mathrm{Me}_{3} \mathrm{NO}$

水合肼与铼杂环丁二烯也能发生锞-碳键插入反应 生成扩环产物锞杂吡咯化合物. 如 Eq. 3 所示, 当 Fischer 卡宾性质较弱的铼杂环丁二烯 $\mathbf{3 8 a}$ 与水合肼反 应时, 主要生成胺基取代碳一锞键插入产物 39a; 而当 Fischer 卡宾性质较强的锞杂环丁二烯 $\mathbf{3 8 b}$ 与水合肼反 应时, 主要生成甲基取代碳一钭键插入产物 39b. 这一 反应提供了一条通过铼杂四元环合成锞杂五元环的新 途径.

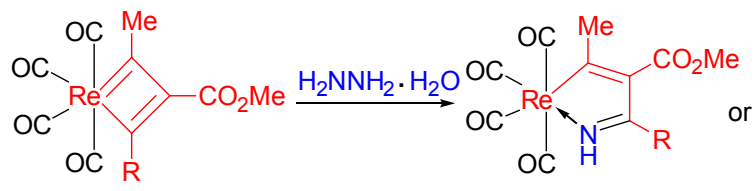
38a: $\mathrm{R}=\mathrm{NEt}_{2}$ 38b: $R=O E t$ 39a: $\mathrm{R}=\mathrm{NEt}_{2}$<smiles></smiles>

通常, 金属杂环丁二烯与炔烃反应形成环戊二烯基 金属配合物，推测这一反应经历了金属苯中间体 ${ }^{[19]}$, 金 属苯的形成也被认为是金属催化炔烃复分解反应中催 化剂失活的重要途径. 但是金属杂环丁二烯与炔烃反应 生成稳定金属苯的报道相对较少 ${ }^{[20]}$.

2007 年, Wright 等 ${ }^{[21]}$ 报道了金属杂环丁二烯 $\mathbf{4 0}$ 在 $\mathrm{AgO}_{3} \mathrm{SCF}_{3}$ 作用下与丙炔酸甲酯的扩环反应(Eq. 4), 首 
次实现了由金属杂环丁二烯到金属苯的转变.

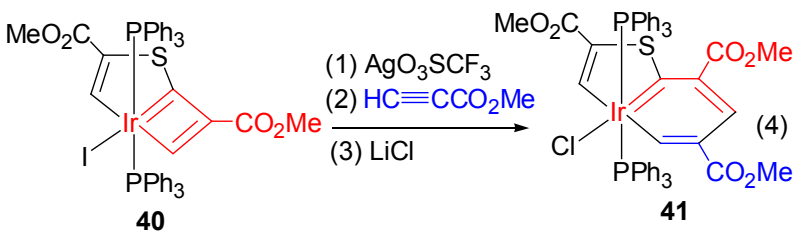

2010 年, Jia 等 ${ }^{[22]}$ 利用烷氧基对金属杂六元环的稳 定化作用, 实现了铼杂环丁二烯 $\mathbf{4 2}$ 和 $\mathbf{4 3}$ 与乙氧基乙炔 的扩环反应(Scheme 11), 成功分离和表征了首例前过 渡系金属苯一一锞杂苯。

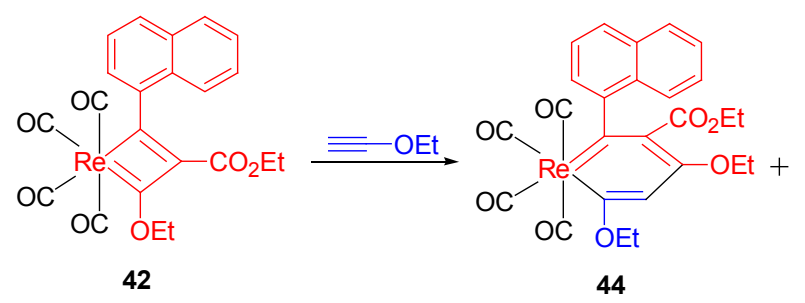<smiles>[R5]C([O-])([O-])Oc1c(OCC)cc(-c2cccc3ccccc23)c(OCC)c1OCC</smiles><smiles>CCOC(=O)C1=C(c2ccccc2)C([O-])([O-])C([O-])([O-])C1(OCC)OCC</smiles>

43

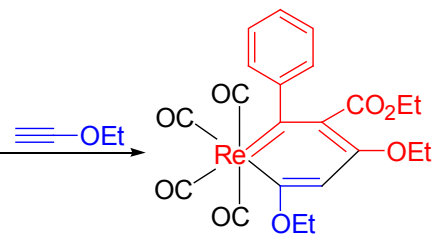

46

\section{Scheme 11}

\section{2 过渡金属杂环丁烯的扩环反应}

\subsection{1 过渡金属杂环丁烯的扩环反应}

金属杂环丁烯是炔烃聚合 ${ }^{[3,23]}$ 、烯炔复分解反应 ${ }^{[24]}$ 和环丙烯化 ${ }^{[25]}$ 等许多重要金属催化反应的中间体. 如 Scheme 12 所示, 金属杂环丁烯与两种烯基金属卡宾结 构互为共振结构 ${ }^{[26]}$, 因此金属杂环丁烯与不饱和化合 物的反应可视为金属杂环丁烯先开环形成烯基金属卡 宾化合物，然后烯基金属卡宾化合物再与不饱和化合物 反应，如金属杂环丁烯与烯烃的反应.

金属杂环丁烯化合物由于具有很大的环张力, 因此 极易与不饱和化合物发生扩环反应，如与腈、羰基化合 物、烯烃、炔烃等发生 $[4+2]$ 加成反应生成六元环化合 物; 与亚硝基化合物、异腈、 $\mathrm{CO}$ 等发生[4+1]加成反应

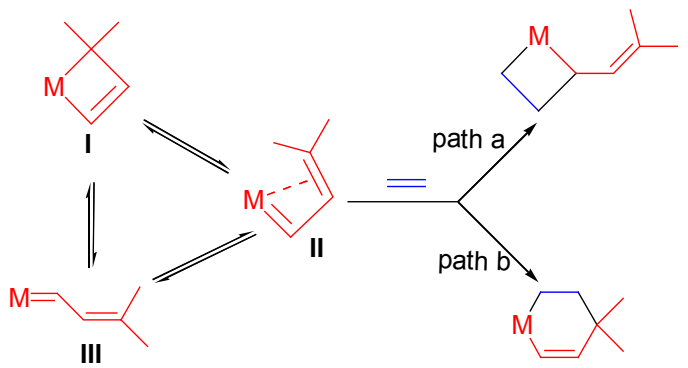

Scheme 12

生成金属杂五元环化合物.

1990 年, Doxsee 等 ${ }^{[27]}$ 研究了钛杂环丁烯 47 与腈的 反应，根据环上取代基及腈的位阻大小，可生成单分子 或双分子腈插入产物. 单分子腈插入反应发生在 $\mathrm{Ti}$-烷 基键中，双分子腈插入反应则分别发生在 $\mathrm{Ti}$-烷基键及 Ti-烯基键中.

当钛杂环丁烯环上的取代基和腈的位阻都较小时, 发生双分子腈插入反应, 如铁杂环丁烯 47a, 47b 与异丁 腈反应生成双分子插入产物 48a, $48 b$ (Eq. 5).

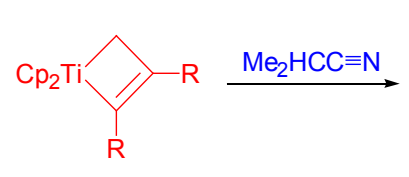

47a, 47b

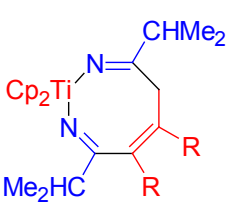

48a, 48b a $\mathrm{R}=\mathrm{Me}, \mathrm{b} \mathrm{R}=\mathrm{Et}$

当钛杂环丁烯取代基或腈的位阻很大时，只生成单 分子插入产物. 如钛杂环丁烯 $\mathbf{4 7}$ 与腈 49 反应生成单分 子插入产物 50 (Eq. 6). 当钛杂环丁烯取代基和腈的位 阻较小时, 生成单分子和双分子腈插入产物的混合物.

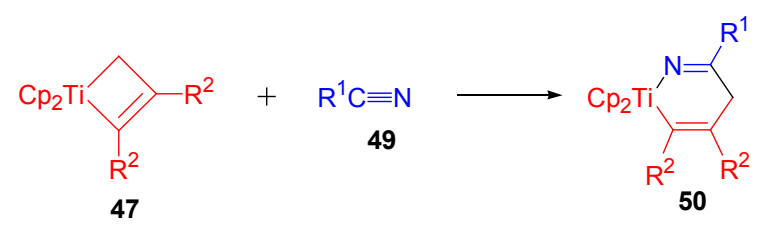

$$
\begin{aligned}
\mathrm{R}^{2}=\mathrm{Ph} ; \mathbf{a} \mathrm{R}^{1} & =\mathrm{Me}, \mathbf{b} \mathrm{R}^{1}=\mathrm{Et}, \mathbf{c} \mathrm{R}^{1}=\mathrm{Me}_{2} \mathrm{CH}, \mathbf{d} \mathbf{R}^{1}=\mathrm{Me}_{3} \mathrm{C}, \\
\mathbf{e} \mathrm{R}^{1} & =\mathrm{C}_{6} \mathrm{H}_{5}, \mathbf{f} \mathrm{R}^{1}=p-\mathrm{FC}_{6} \mathrm{H}_{4}, \mathbf{g ~ R}^{1}=p-\mathrm{MeOC}_{6} \mathrm{H}_{4}, \\
\mathbf{h} \mathrm{R}^{1} & =p-\mathrm{MeC}_{6} \mathrm{H}_{4}, \mathbf{i} \mathrm{R}^{1}=0-\mathrm{MeC}_{6} \mathrm{H}_{4}, \mathbf{j} \mathrm{R}^{1}=p-\mathrm{CF}_{3} \mathrm{C}_{6} \mathrm{H}_{4}, \\
\mathbf{k} \mathrm{R}^{1} & =\mathrm{C}_{6} \mathrm{~F}_{5} \\
\mathrm{R}^{2}=\mathrm{Et} ; \mathrm{R}^{1}=\mathrm{CMe}_{3} &
\end{aligned}
$$

1991 年, Doxsee 等 ${ }^{[28,27 b]}$ 又研究了钛杂环丁烯与醛、 酮的反应. 与腈的反应类似, 钛杂环丁烯与醛、酮也发 生 $[4+2]$ 环化反应生成钛杂六元环化合物，且醛、酮及 钛杂环丁烯上取代基的位阻决定了生成的扩环产物为 Ti-烷基或 Ti-烯基插入产物. 如 Eq. 7 所示, 钛杂环丁烯 47c 与酮反应单一地生成 Ti-烷基插入产物. 


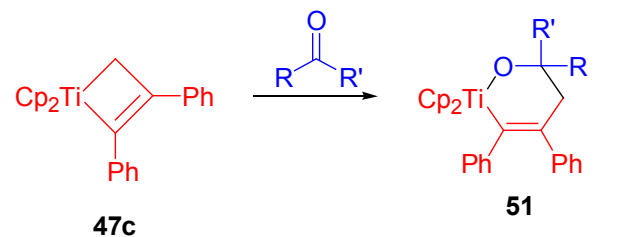<smiles>[R]C(=O)C([R])=[C]C(C)=O</smiles>

此外, 47c 也能与胍发生扩环反应得到钛杂六元环 产物 $\mathbf{5 2}^{[29]}$ (Eq. 8).

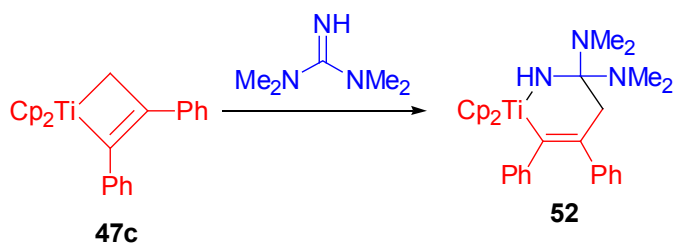

2003 年, Hessen 等 $^{[30]}$ 在研究环内钛卡宾的合成及其 反应性时, 发现环内钛卡宾 53 能与一分子二苯乙炔发 生[2+2]环加成反应生成钛杂环丁烯 54, 54 与 55 在反应 体系中以 $3: 1$ 比例共存. 化合物 54 与三甲基膦作用时 可转化成 $\mathbf{5 5}$, 化合物 $\mathbf{5 5}$ 也可通过解离三甲基膦转化为 54. 在 $-20{ }^{\circ} \mathrm{C}$ 条件下, 钛杂环丁烯 54 与一分子 2-丁炔反 应生成新的钛杂环丁烯 56. 56 在常温下可异构生成扩环 产物钛杂环已二烯 57 (Scheme 13).

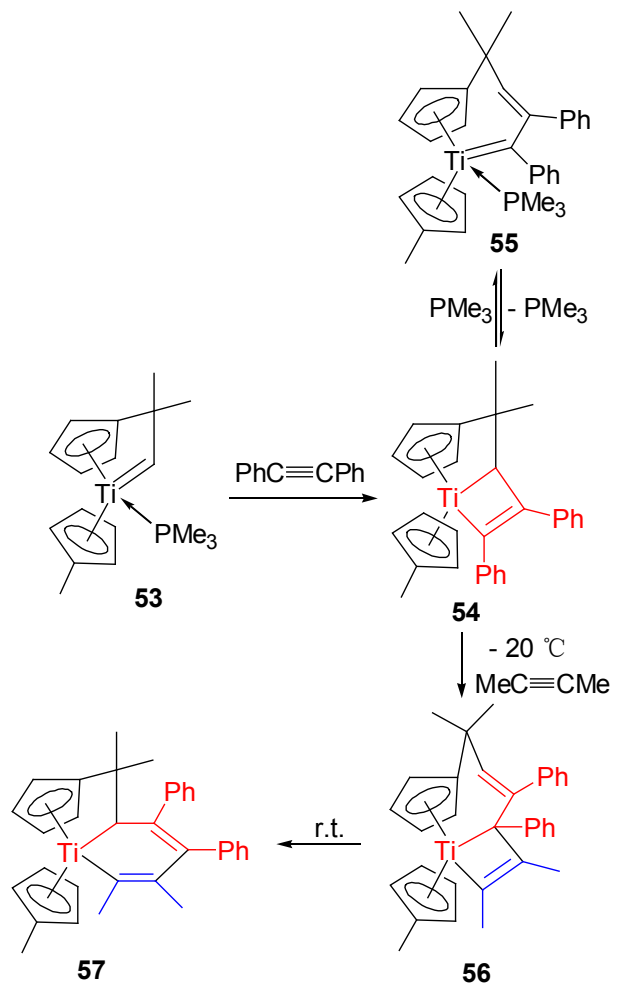

Scheme 13
烯烃与金属杂环成二烯及金属杂环丁烷的反应在 合成方法学上已取得了重要的进展 ${ }^{[31]}$, 而烯烃与金属 杂环丁烯反应的研究相对较少. 2008 年, O'Connor 等 ${ }^{[32]}$ 报道了第一例金属杂环丁烯与烯烃的 $[4+2]$ 环加成反 应. 如 Eq. 9 所示, 钴杂环丁烯 58 与过量马来酸酐在甲 苯中加热生成 endo 和 exo 两种立体构型的扩环产物.

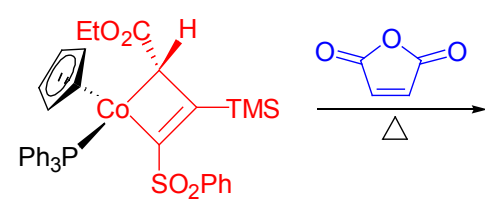

58

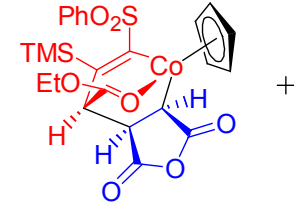

59-exo

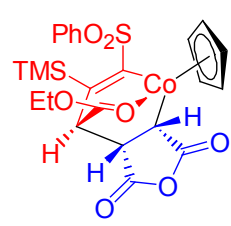

该反应的机理是金属杂环丁烯首先转化成烯基卡 宾, 然后再进一步与马来酸酐发生 $[4+2]$ 环加成反应, 最后生成扩环产物.

金属杂环丁烯除了与不饱和化合物如腈、羰基化合 物、烯烃和炔烃发生 $[4+2]$ 环化反应外，还可与亚硝基 化合物、异腈和 $\mathrm{CO}$ 等发生 $[4+1]$ 扩环反应.

1986 年, Grubbs 等 ${ }^{[33]}$ 详细研究了 CO 与钛杂环丁烯 47a 的反应，外加 1 equiv.三甲基膦情况下，钛杂环丁烯 $47 \mathbf{a}$ 与 $\mathrm{CO}$ 反应得到 60 . 为了明晰 60 的形成机理, 他们 进行了同位素标记和低温实验，发现，在-30 ${ }^{\circ} \mathrm{C}$ 条件下， $\mathrm{CO}$ 区域选择性地插入到位阻相对较小的 $\mathrm{Ti}$-烷基键上 生成钛杂环戊烯酮 61. 但是化合物 61 不稳定, 很快重 排成 60 (Scheme 14).

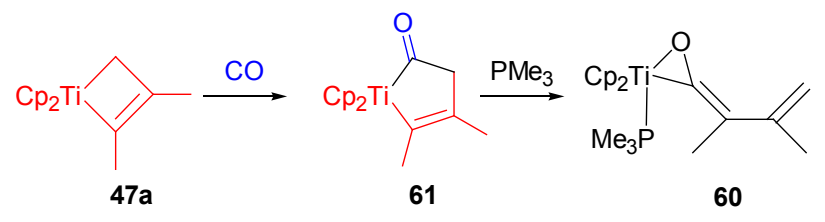

Scheme 14

1986 年, Yamazaki 等 ${ }^{[34]}$ 利用铑配合物 62 与对甲苯 基异腈反应合成了 $\alpha$-亚氨基取代的铑杂环丁烯化合物 63. 虽然 63 与不饱和化合物如炔烃, $\mathrm{CS}_{2}, \mathrm{MeSCN}$ 等都 能发生插入反应，但是仅与 $\mathrm{CO}$ 反应可得到稳定的扩环 产物 64 (Scheme 15), 其它反应生成的产物都不稳定, 容易进一步发生还原消除. 


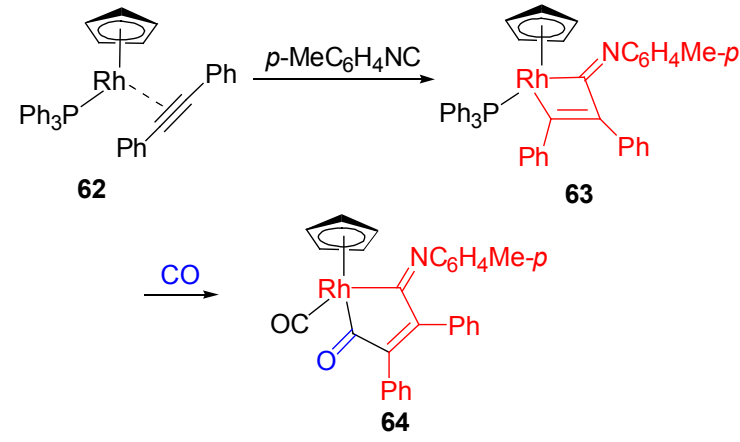

Scheme 15

1996 年, Werner 等 ${ }^{[35]}$ 研究了铑配合物 65 与烷基异 腈的插入反应, 首先 65 与甲胩发生单分子插入反应生 成铑杂环丁烯化合物 66, 随后 66 还能进一步与过量的 异腈反应, 生成双分子异腈插入的扩环产物铑杂环戊二 烯化合物 67 (Scheme 16). 反应过程是甲胩取代铑中心 的三异丙基钩配体, 配位的甲胩进一步插入到金属杂环 丁烯的 Rh-烯基键形成配位不饱和的铑杂环戍二烯化合 物, 第二分子异腈再配位到金属中心形成最终产物.

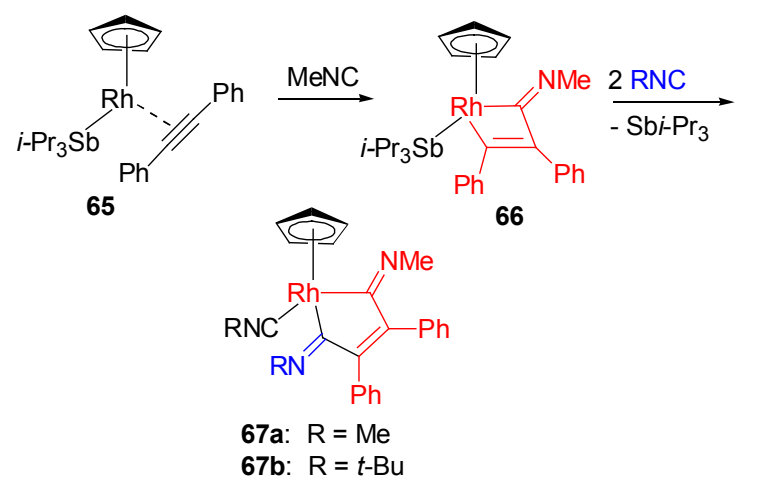

Scheme 16

1996 年, Ganter 等 ${ }^{[36]}$ 通过钛亚乙烯化合物与炔烃反 应合成了 $\alpha$-亚甲基取代的钛杂环丁烯化合物 69. 虽然 69 与腈、酮及大部分的炔烃都不反应, 但能与环己基异 腈发生反应, 生成单分子异腈插入的产物 70 (Scheme 17).

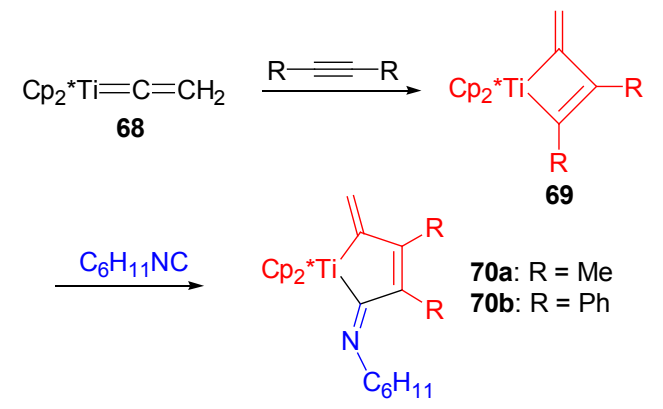

Scheme 17

2009 年, $O^{\prime}$ Connor 等 ${ }^{[37]}$ 报道了钴杂环丁烯化合物
58 与亚硝基化合物的反应，反应生成扩环的 $\eta^{2}(N, O)-N, N$-二烷基羟氨配合物，这一反应不仅具有区 域选择性, 还具有立体选择性. 亚硝基化合物的位阻对 反应的立体选择性影响很大，当大位阻的 2-甲基-2-亚 硝基丙烷与化合物 $\mathbf{5 8}$ 反应时, 生成单一 trans 产物; 而 位阻较小的亚硝基苯与化合物 $\mathbf{5 8}$ 反应时, 生成 cis 产物 与 trans 产物比例为 $8: 1$ (Scheme 18).

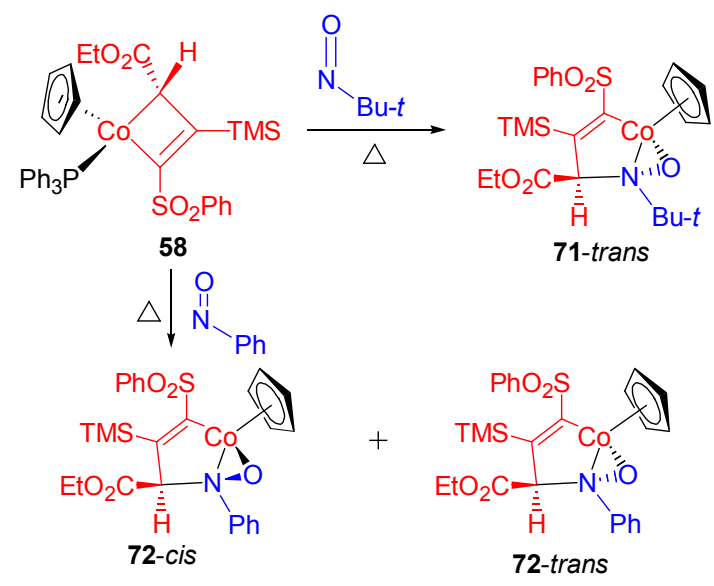

Scheme 18

此外，环内含一个杂原子的金属杂环丁烯类化合物 的扩环反应也受到了人们广泛的关注.

在进行了金属杂环丁烯化学的研究基础上, 1989 年, Doxsee 等 ${ }^{[38]}$ 又把研究领域拓展到了含杂原子的金属 杂环丁烯化合物. $\mathrm{Cp}_{2} \mathrm{Ti}=\mathrm{CH}_{2}$ 前体 73 与 1 当量的新戊 腈发生 $[2+2]$ 环加成反应合成了含氮原子的钛杂环丁烯 74, 74 能进一步与新戊腈反应, 通过[4+2]环加成反应 生成含两个氮原子的钛杂六元环化合物 75 (Scheme 19).

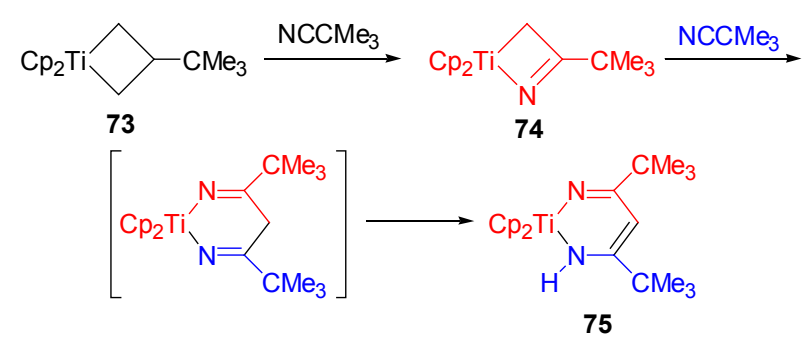

Scheme 19

1989 年, Alexander 等 ${ }^{[39]}$ 研究了异腈对羰基锰化合 物的插入反应. 羰基锰化合物 76 与两分子对甲苯基异 腈反应生成 1-锰-2-氮杂环丁烯化合物 77, 化合物 77 可 再与一分子异腈反应生成 Mn-N 键插入的扩环产物 78, 78 为环内卡宾化合物(Scheme 20). 化合物 78 的形成机 理可能是: 首先异腈取代 77 中配位的亚胺基得到中间 体, 然后亚胺孤对电子对亲核进攻异腈上的碳原子, 最 后，苄基上的氢转移到异腈的 $\mathrm{N}$ 上形成化合物 $\mathbf{7 8}$. 


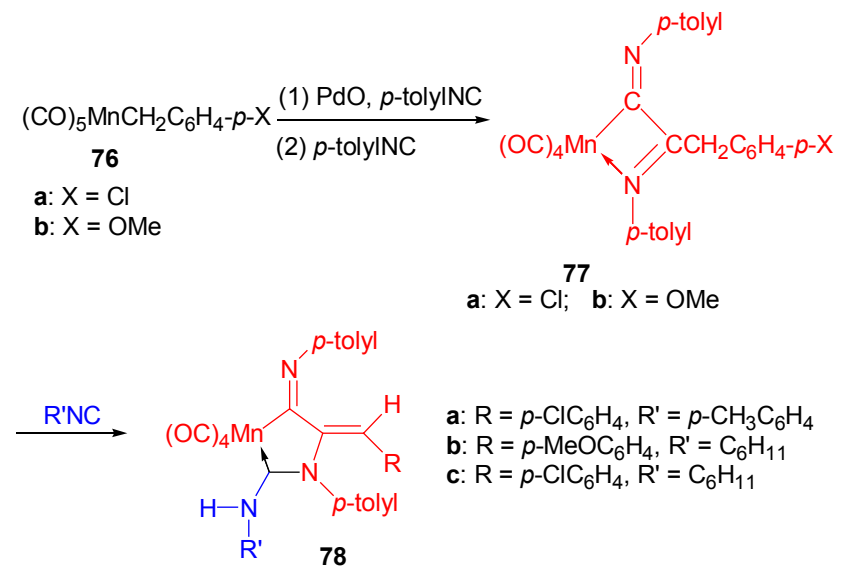

\section{Scheme 20}

1990 年, Heathcock 等 ${ }^{[40]}$ 研究了炔烃与锞配合物的 反应. 在 $\mathrm{Me}_{3} \mathrm{NO}$ 作用下, 钭配合物 79 很快转化成环状 化合物 80,80 可在温和条件下与末端炔烃迅速反应生成 含环外双键的扩环产物 81, 81 不稳定, 在 Lewis 碱的作 用下转化成铼杂呋喃化合物 82 (Scheme 21).

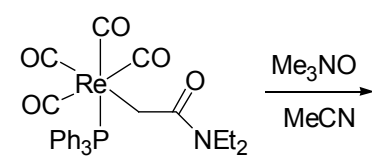

79

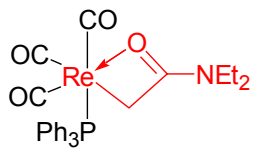

80

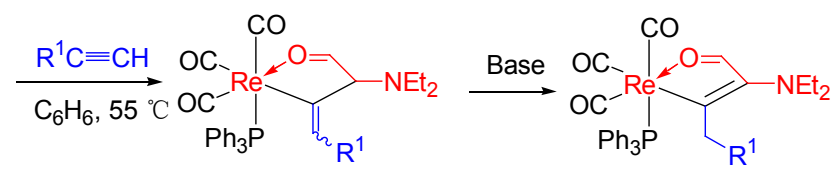
81

$\mathrm{R}^{1}=\mathrm{H}, \mathrm{Me}, \mathrm{Et}, i-\mathrm{Pr}, t-\mathrm{Bu}, \mathrm{Ph}, \mathrm{SiMe}_{3}, \mathrm{CO}_{2} \mathrm{Et}, \mathrm{CO}_{2} \mathrm{Me},\left(\mathrm{CH}_{2}\right)_{6} \mathrm{CH}_{3}$

\section{Scheme 21}

一般情况下, 含吸电子取代基的炔烃比较容易插入 到 $\mathrm{M}-\mathrm{C}$ 键之中, 而含给电子基的炔烃不易发生这一反 应. 上述反应能够顺利进行是因为反应并非炔烃直接插 入到 $\mathrm{M}-\mathrm{C}$ 键，而是通过氧化插入反应进行的.

1991 年, Andersen 等 ${ }^{[41]}$ 研究了钓杂四元环的反应 性，向钉杂氧杂环丁烯 83 的苯溶液中加入 1 当量的 $\mathrm{CO}_{2}$ 迅速发生 $[4+2]$ 环加成反应, $\mathrm{CO}_{2}$ 插入到 $\mathrm{M}-\mathrm{O}$ 键中生成 钓杂六元环产物 84, 分离产率为 $42 \%$ (Eq. 10).

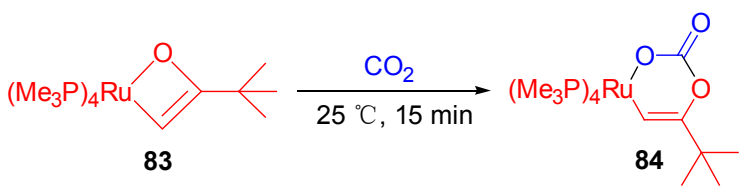

1992 年, Riley 等 ${ }^{[42]}$ 通过 $\mathrm{RhCl}\left(\mathrm{PPh}_{3}\right)_{3}$ 对膦衍生物 85 的插入反应合成了铑杂磷杂环丁烯化合物 86. 在 $\mathrm{CO}$ 气 氛中 86 可转化为 $\mathrm{CO}$ 插入产物 $\mathbf{8 7}$, 其产率为 $80 \%$

(Scheme 22).

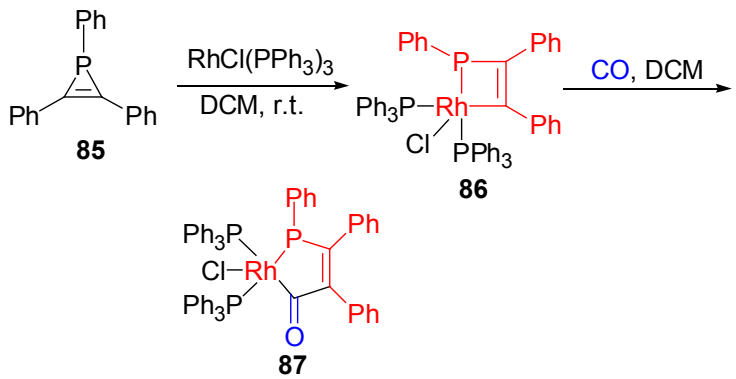

Scheme 22

2003 年, Osakada 等 ${ }^{\left[{ }^{[3]}\right]}$ 研究了铂杂四元环化合物与 乙炔基二茂铁的反应. 在 $60{ }^{\circ} \mathrm{C}$ 甲苯溶液中，铂杂硅杂 环丁烯与乙炔基二茂铁反应生成六元金属杂环化合物 89 (Eq. 11)

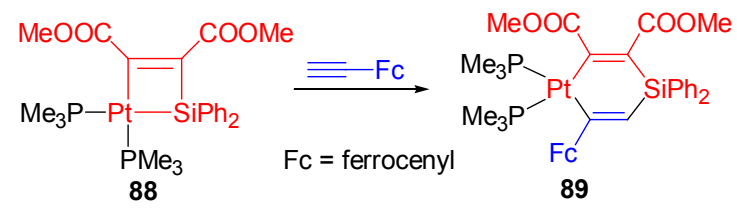

2013 年, Carmona 等 ${ }^{[44]}$ 在研究具有受阻 Lewis 酸碱 对性质的铱配合物 90 的反应性时, 通过 90 与乙炔反应 合成了含环外双键的铱杂四元环化合物 91.91 臭氧解得 扩环产物 92, 推测 92 的形成可能经历了含环氧乙烷结 构的中间体 $\mathbf{L}$ (Scheme 23). 此外, 91 在高镇酸钾的氧化 下除可生成开环产物 93 外也生成扩环产物 92.

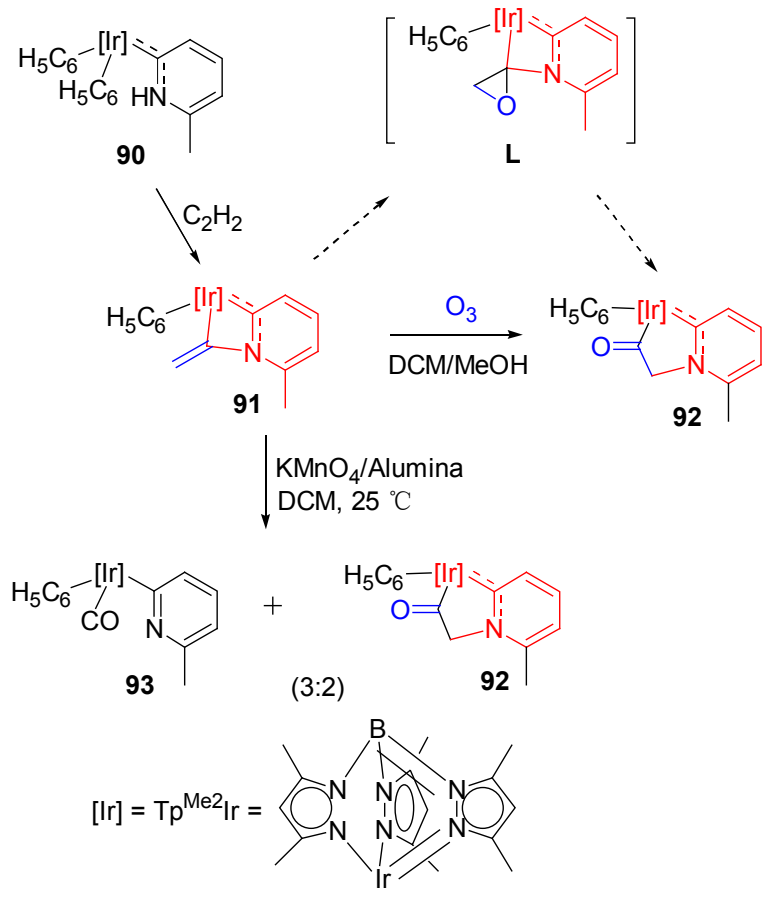

Scheme 23 


\subsection{2 含金属杂环丁烯单元的稠环化合物扩环反应}

1995 年, Takahashi 和合作者 ${ }^{[45]}$ 通过二炔基硅烷 94 与低价态锆化合物 $\left[\mathrm{Cp}_{2} \mathrm{Zr}\right]$ 反应, 获得结构中含有锆杂 环丁烯单元的稠环化合物 95. 如 Eq. 12 所示, 该方法具 有很好的普适性，可获得含多种取代基的稠环产物.
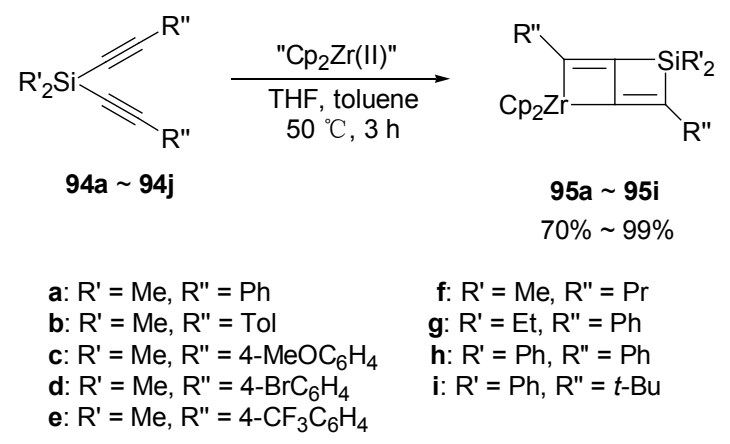

$$
\text { f: } R^{\prime}=M e, R^{\prime \prime}=P r
$$$$
\text { g: } R^{\prime}=E t, R^{\prime \prime}=P h
$$$$
\text { h: } R^{\prime}=P h, R^{\prime \prime}=P h
$$$$
\text { i: } \mathrm{R}^{\prime}=\mathrm{Ph}, \mathrm{R}^{\prime \prime}=t-\mathrm{Bu}
$$

化合物 95 含有两个 $\mathrm{Zr}-\mathrm{C}$ 键和两个 $\mathrm{Si}-\mathrm{C}$ 键, 具 有丰富的反应性. 2001 年开始, $\mathrm{Xi}$ 等系统研究了化合物 95a $\sim 95 \mathbf{i}$ 及其钛类似物与腈 ${ }^{[14,46]}$ 、炔烃 ${ }^{[47]}$ 和其它不饱和 化合物 ${ }^{[48]}$ 的扩环反应. 与金属杂环丁烯与不饱和化合 物的简单扩环反应机理不同, 稠环化合物 95 的扩环反 应大多经历了环骨架重排 $(\mathbf{A}, \mathbf{B}, \mathbf{C}$ 和 D) (Scheme 24), 再进一步与不饱和化合物反应生成扩环产物, 化合物 95 的扩环反应详见 $\mathrm{Xi}$ 研究组的最近两篇综述 ${ }^{[49,50]}$.

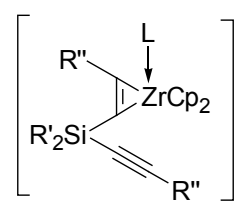

A

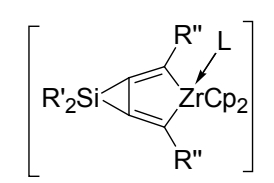

B

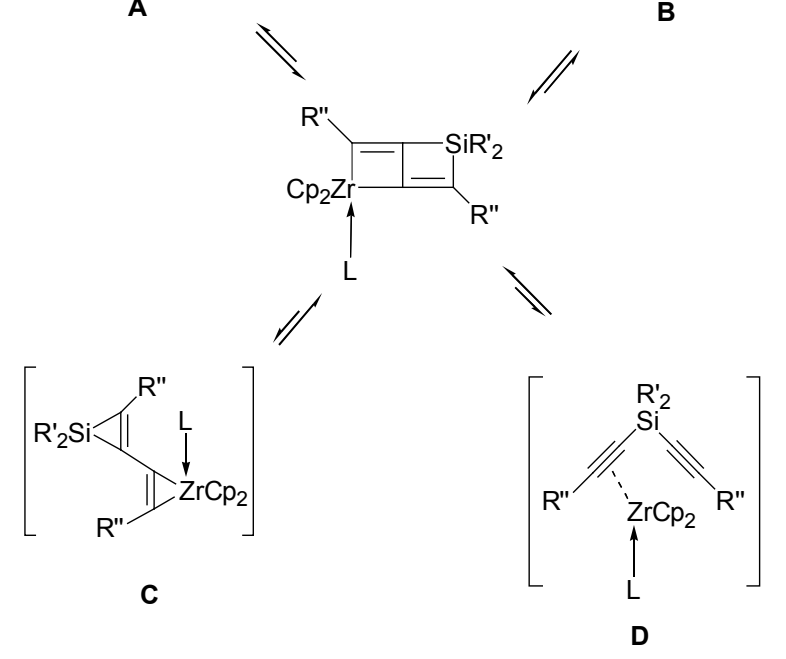

Scheme 24

\section{3 过渡金属杂五元环的扩环反应}

\section{1 过渡金属杂环戊二烯的扩环反应}

金属杂环戍二烯化合物是合成共轭有机化合物的
重要中间体 ${ }^{[51]}$, 它可与炔烃 ${ }^{[52]}$ 或腈 ${ }^{[53]}$ 反应生成苯的衍 生物，与异腈 ${ }^{[54]} 、 \mathrm{CO}$ 、异氰酸酯、羰基化合物 ${ }^{[5]}$ 等反应 生成环戊二烯衍生物. 通常认为金属杂环戊二烯化合物 与不饱和化合物的反应可能经历了不饱和化合物对金 属一碳键的插入反应，但生成的扩环产物很少被分离. 目前，金属杂环戍二烯化合物的扩环研究还相对较少.

1997 年, Takahash 和 Xi 等 ${ }^{[45 b]}$ 通过锆杂环戊烯化合 物 96 与二炔基硅烷反应合成了硅基取代的锆杂环戊二 烯化合物 97 并研究了其反应性. 研究发现：锆杂环戊二 烯化合物 97 在 THF 中回流 $3 \mathrm{~h}$ 发生碳骨架重排, 形成 分子内炔基插入的含锆杂六元环单元的稠环化合物 98 (Scheme 25).
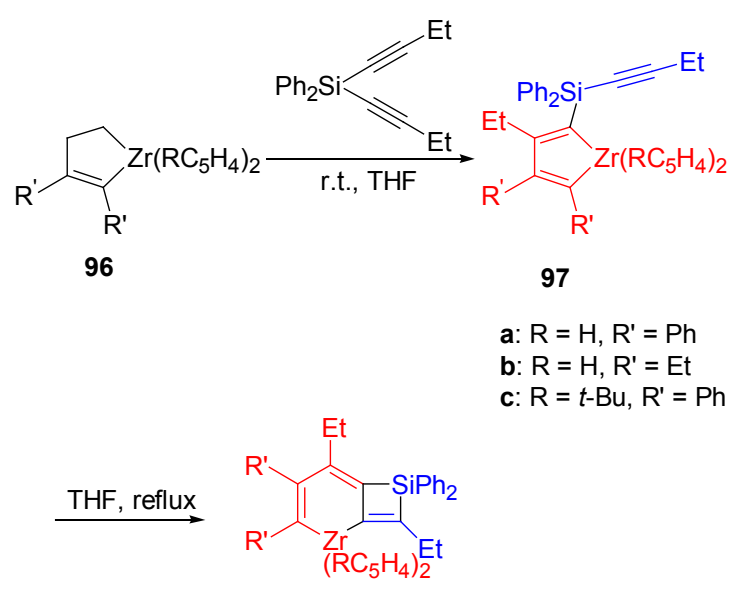

a: $R=H, R^{\prime}=P h$ b: $R=H, R^{\prime}=E t$ c: $\mathrm{R}=t-\mathrm{Bu}, \mathrm{R}^{\prime}=\mathrm{Ph}$

98

\section{Scheme 25}

2000 年, 他们 ${ }^{[56]}$ 又研究了锆杂环戊二烯化合物 99 与 1-氯-1-三甲基硅基甲基锂的反应，生成卡宾碳对 $\mathrm{Zr}-\mathrm{C}$ 键插入的扩环产物锆杂环己二烯化合物 100 (Eq. 13).

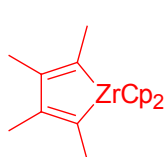

99

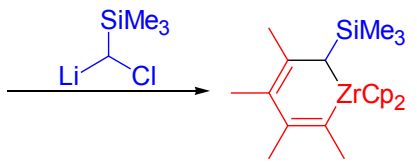

100
2002 年, Chin 等 ${ }^{[57]}$ 在研究铱杂环戊二烯与末端炔烃 反应选择性地合成烯炔化合物的机理时发现，炔基取代 的铱杂环戊二烯化合物 $\mathbf{1 0 1}$ 与 $\mathrm{HBF}_{4}$ 发生插入反应生成 六元铱杂环化合物. 根据反应体系是否含有过量乙腈可 生成不同的扩环产物：无乙腈参与反应时，生成铱杂环 己二烯 102, 铱杂环已二烯 102 结构上含有一个环外双 键和一个稀有的芳基 agostic 氢; 过量乙腈参与反应时, 则生成铱苯化合物 103. 另外，铱杂环己二烯化合物 102 与过量 $\mathrm{HBF}_{4}$ 及乙腈反应也能转化成铱苯 103 (Scheme 26). 


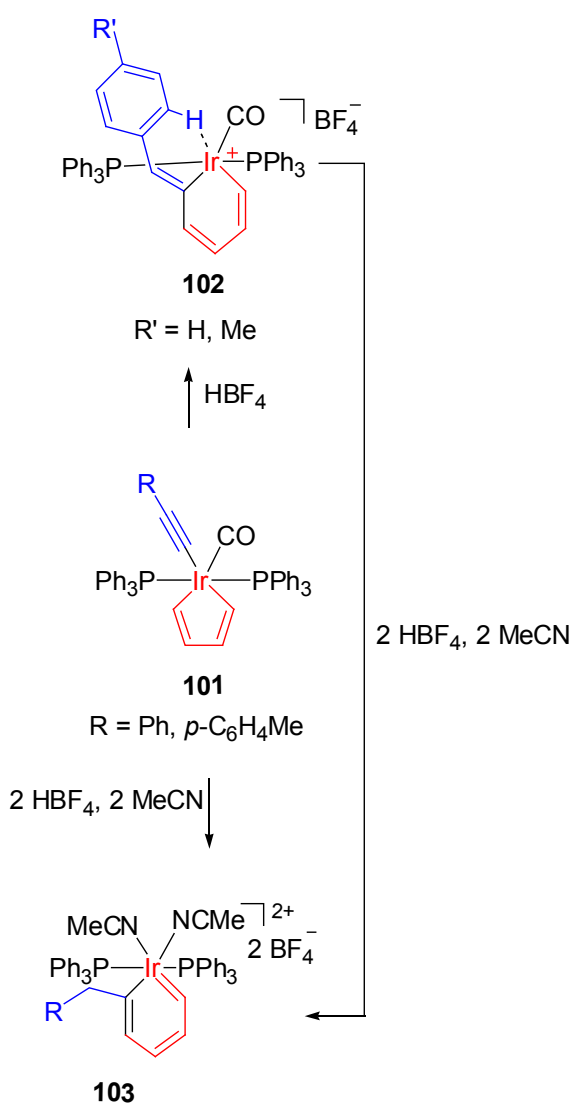

Scheme 26

化合物 102 的形成机理可能是 101 在质子的作用下 先生成铱亚乙烯基化合物中间体, 随后铱杂环戍二烯的 $\alpha$-碳进攻亲电的铱亚乙烯基的 $\alpha$-碳, 从而形成最终产物 102.

实际上，金属杂环戊二烯是合成金属苯的重要前 体. 自 1982 年 Roper 等 ${ }^{[58]}$ 利用硫代羰基的迁移插入合成 第一例稳定的金属苯以来, 该课题组发展了一系列通过 金属杂环戊二烯的扩环反应合成金属苯的高效方法. 2008 年, Wright 等 ${ }^{[99]}$ 合成了中性的硫代羰基取代的铱杂 环戊二烯化合物 104, 104 与 $\mathrm{CF}_{3} \mathrm{SO}_{3} \mathrm{Me}$ 反应, 硫代羰基 中的碳原子迁移插入到铱杂环戊二烯单元中, 形成扩环 产物铱苯 105 (Eq. 14).

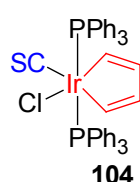

$$
\underset{\text { (2) } \mathrm{LiCl}, 56 \%}{\stackrel{(1)}{ } \Delta / \mathrm{CF}_{3} \mathrm{SO}_{3} \mathrm{Me}}
$$

104

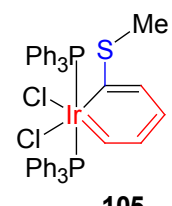

105
2009 年, 他们 ${ }^{[60]}$ 又合成了硫代羰基取代的铱杂环 戊二烯化合物 106, 并研究了其扩环反应. 与 104 的反 应性类似, 在加热条件下, 硫代羰基中的碳原子迁移插 入到铱杂环戊二烯单元中, 形成 $\eta^{2}-C(S)$ 取代的扩环产 物铱苯 107. 107 甲基化后生成甲硫基取代的铱苯 108 ,
107 还可在酸和醇作用下与腈发生 $[3+2]$ 关环反应生成 稠环化合物 109 (Scheme 27).
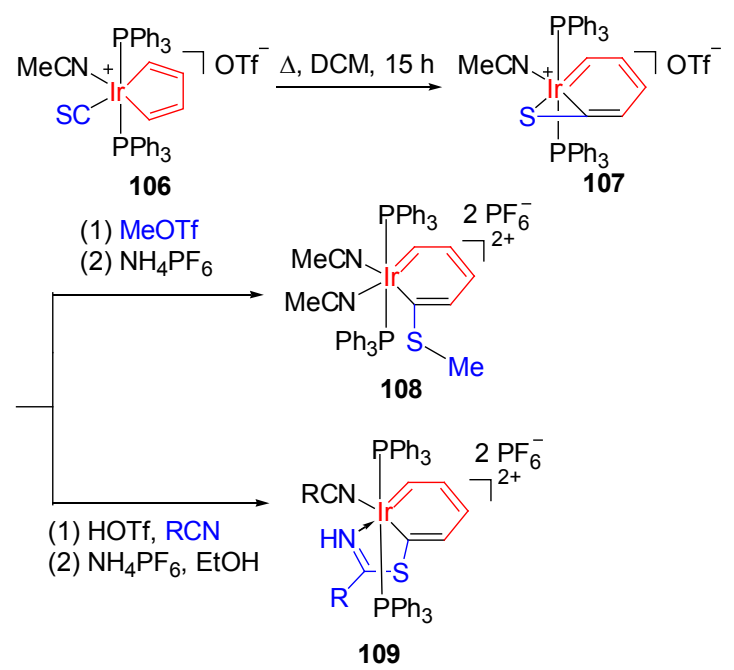

a: $R=M e$

b: $\mathbf{R}=p$-tolyl

Scheme 27

2011 年, Wright 等 ${ }^{[61]}$ 又研究了 $\mathrm{CO}$ 取代的阳离子型 铱杂环戊二烯化合物 110 与丙炔酸甲酯的反应. 在加热 的条件下, 110 与丙炔酸甲酯反应生成扩环产物铱苯并 呋喃 111. 111 的生成可能经历了铱亚乙烯基中间体 $\mathbf{E}$ (Scheme 28).

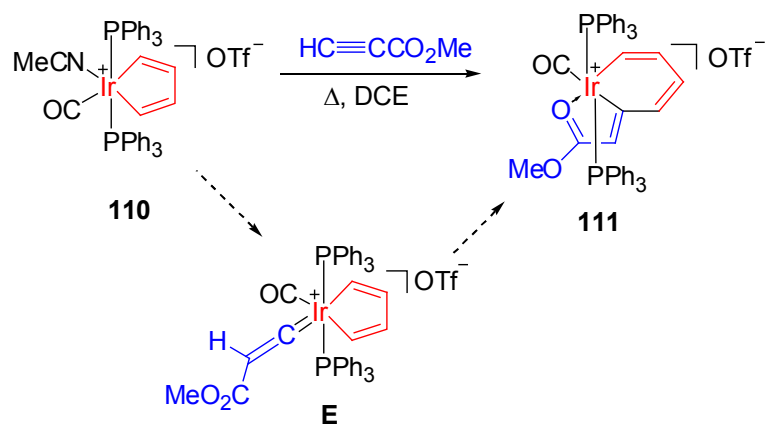

Scheme 28

此外, 环内含杂原子的金属杂环戊二烯类化合物也 是一类重要的反应活性中间体 ${ }^{[62]}$, 它能发生有趣的扩 环反应得到一系列结构新颖的金属杂环化合物.

2009 年, 我们课题组 ${ }^{[63]}$ 研究了杂原子取代的金属 杂环戊二烯化合物一一锇呋喃 112 与炔烃的反应，在 $\mathrm{CHCl}_{3}$ 中, 112 与过量的苯乙炔反应 $1 \mathrm{~h}$ 可高产率生成两 分子炔烃插入的九元环化合物 113a 和 113b. 此外, 化 合物 113a 和 113b 可进一步与 $\mathrm{PMe}_{3}$ 发生配体取代反应 单一地转化成化合物 114. 室温下 $\mathrm{CHCl}_{3}$ 中, 112 与 $\mathrm{HC} \equiv \mathrm{CCH}(\mathrm{OH}) \mathrm{Ph}$ 反应 $1 \mathrm{~h}$ 则高产率得到单分炔插入的九 元环化合物 115 (Scheme 29). 
$\underset{93 \%}{\stackrel{\mathrm{Cl}}{\mathrm{C}}}$

112
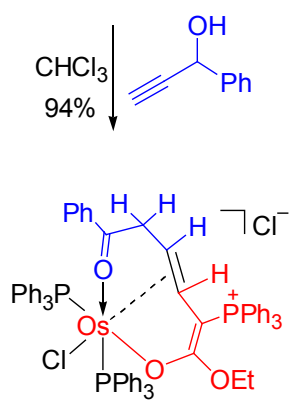

115

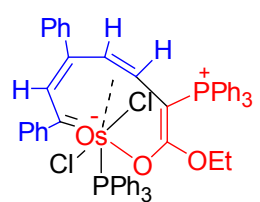

113a

$+$

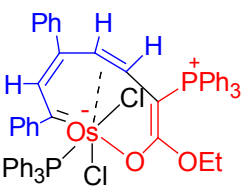

$113 b$

$\mathrm{PMe}_{3}$

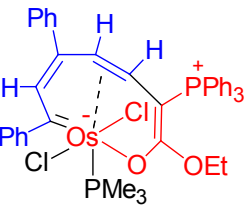

114

Scheme 29

推测 113 的形成机理如下图所示(Scheme 30): 首 先, 苯乙炔取代锇呋喃 112 的一个 $\mathrm{PPh}_{3}$ 配体形成中间体 $\mathbf{F}$, 然后配位的炔基与锇卡宾发生 $[2+2]$ 环加成反应开 环形成七元环 $\mathbf{G}, \mathbf{G}$ 再插入一分子苯乙炔形成九元环中 间体 $\mathbf{H}$, 最后环内双键配位到锇中心得到稳定的产物 113. 推测九元环化合物 115 的形成也经历了类似的扩 环过程.

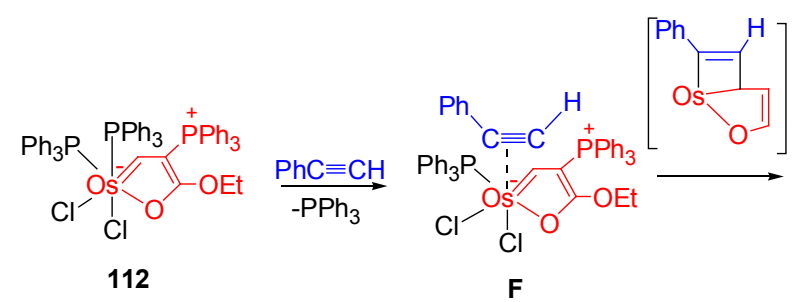

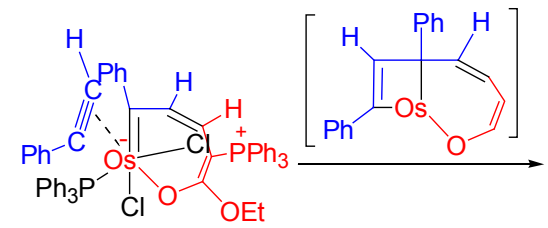

G

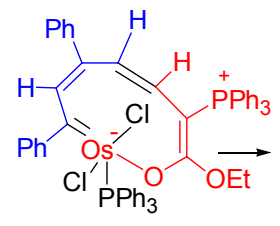

H

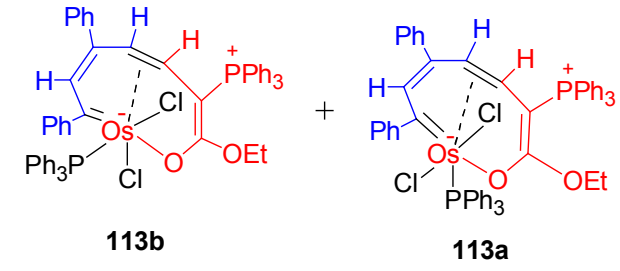

Scheme 30

\section{2 过渡金属杂环内联烯的扩环反应}

与上述金属杂环化合物相比, 金属杂环内联烯化合 物是一类环张力更大的化合物, 其与不饱和化合物的反 应性更加丰富 ${ }^{[64]} .1999$ 年, Rosenthal 等 ${ }^{[65]}$ 合成了锆杂环 内多烯化合物 116 并研究了其与 $\mathrm{CO}_{2}$ 的反应性, 116 可 与 $\mathrm{CO}_{2}$ 发生双分子插入反应, 生成扩环产物 117 (Eq. $15)$.

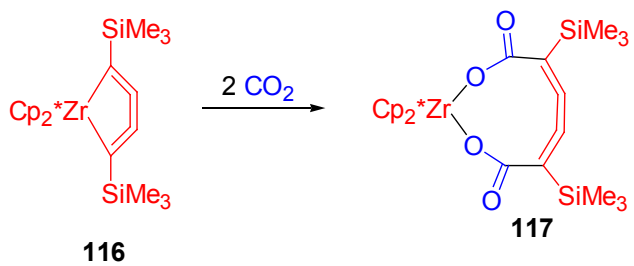

2012 年, Erker 等 ${ }^{[66]}$ 通过 $\left[\mathrm{Cp}_{2} \mathrm{Zr}\right]$ 与烯炔化合物反应 合成了锆杂五元环内联烯化合物 118 并研究了其与不饱 和化合物的扩环反应，环上取代基对 $\mathbf{1 1 8}$ 的反应性具有 重要影响. 铅杂五元环内联烯化合物 $118 \mathrm{a}$ 与苯甲醛反 应生成两分子醛插入的扩环产物 119 , 与乙腈反应生成 $\mathrm{C} \equiv \mathrm{N}$ 插入的扩环产物 120, 与 2-甲基-4-三甲基硅基-1丁烯-3-炔发生炔基插入反应生成七元扩环产物 121; 而 87b 与 2-甲基-4-三甲基硅基-1-丁烯-3-炔则发生 1,4-加 成产物, 生成九元环扩环产物 122 (Scheme 31).
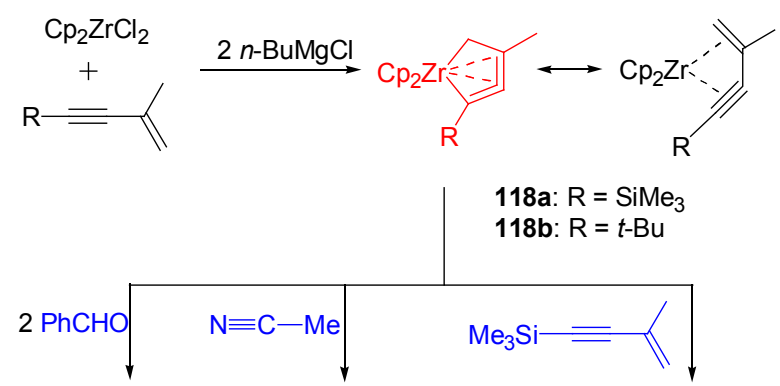

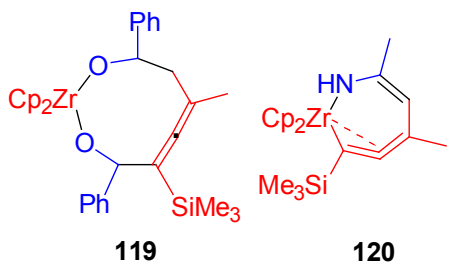<smiles></smiles>

or<smiles>CC1=C(C(C)(C)C)C(=[Ge])C(C(C)(C)C)=C(C)CC1</smiles>

Scheme 31

2013 年, 我们 ${ }^{[67]}$ 报道了锇杂五元环内联烯化合物 124 的合成及其扩环反应. $\eta^{2}$-炔基锇配合物 123 与三溴 吡啶鎓反应高产率得到锇杂五元环内联烯化合物 124. 
理论计算表明 124 具有较大的环张力, 能量上有发生扩 环反应的趋势. 进一步实验表明，在 DMF 溶液中 100 ${ }^{\circ} \mathrm{C}$ 条件下与 $\mathrm{NaBr}$ 反应 $3 \mathrm{~h}$, 化合物 $\mathbf{1 2 4}$ 确实能够转化成 锇杂六元环内联烯化合物 125. 另外, 124 中烯基上的溴 也可被 SCN 取代, 在加热条件下形成六元锇杂环内联 烯化合物 127 (Scheme 32).

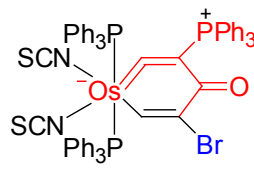

125

$$
\begin{gathered}
\mathrm{NaBr}, \mathrm{DMF} \\
100{ }^{\circ} \mathrm{C}, 3 \mathrm{~h} \\
81 \%
\end{gathered}
$$

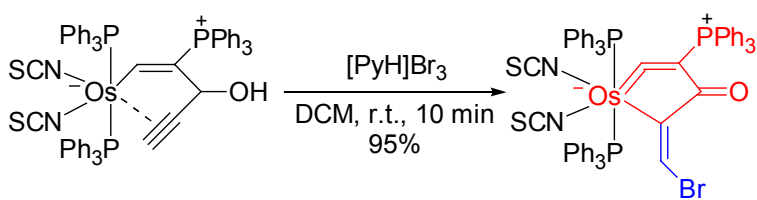

123

124

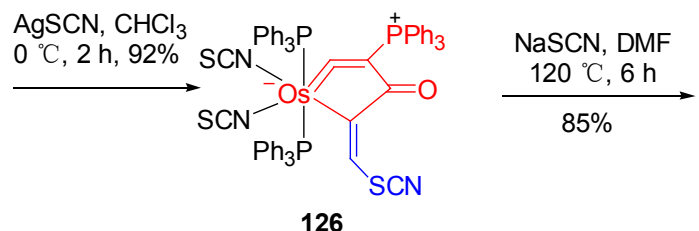

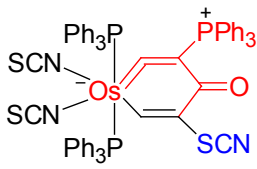

127

Scheme 32

\section{3 过渡金属杂环戊烯的扩环反应}

虽然金属杂环戊烯与不饱和化合物的扩环反应是 合成多种有机化合物的有效途径 ${ }^{[68]}$, 但金属杂环戊烯 扩环产物的成功分离类子并不多. 1993 年, Takahashi 等 ${ }^{[69]}$ 研究了锆杂环戊烯 128 与醛的反应, 在 $0{ }^{\circ} \mathrm{C}$ 或室温 条件下, 醛插入化合物 128 的 Zr-烷基键形成氧杂锆杂 七元环化合物 129 (Eq. 16).

2007 年, 我们 ${ }^{[70]}$ 通过 $\mathrm{HC} \equiv \mathrm{CCH}(\mathrm{OH}) \mathrm{C} \equiv \mathrm{CH}$ 与 cis- $\mathrm{IrHCl}_{2}\left(\mathrm{PPh}_{3}\right)_{3}$ 反应高产率合成了铱杂五元环化合物 131. 131 在空气氛下与三正丁基膦反应, 除生成氧化产 物 132 外, 还生成少量的氧插入扩环产物 133 (Scheme 33). 化合物 133 为一个共轭碳桥连双核铱杂六元环结 构, 具有优良的电化学性能、空气和热稳定性.

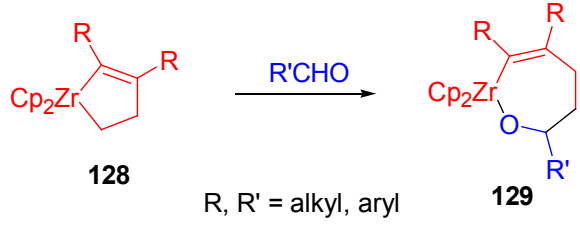

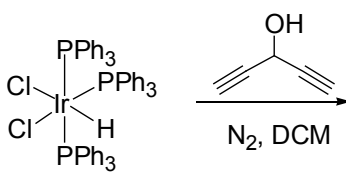

130

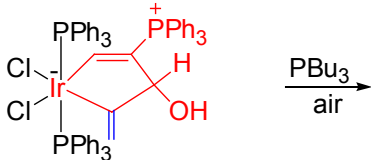

131

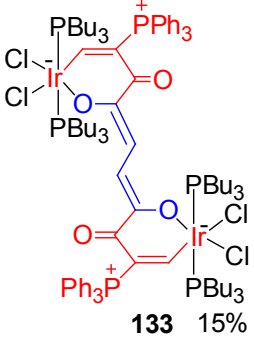

Scheme 33
环内含杂原子的金属杂环戊烯也是一类具有丰富 反应性的物种 ${ }^{[71]}$, 特别是羟基配位的金属乙烯基五元 环化合物，它可与酸快速反应离去羟基形成卡宾、卡拜、

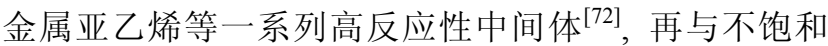
底物反应或发生分子内 $\mathrm{C}-\mathrm{H}$ 活化形成各种扩环产物. 2009 年以来, 我们 ${ }^{[73 ~ 78]}$ 对着基配位的锇乙烯基五元环 化合物的合成及其扩环反应进行了详细研究. 我们通过 $\mathrm{OsCl}_{2}\left(\mathrm{PPh}_{3}\right)_{3}$ 与炔醇衍生物反应，合成了一系列含有不 同取代基的钱乙烯基化合物 136 (Eq. 17).

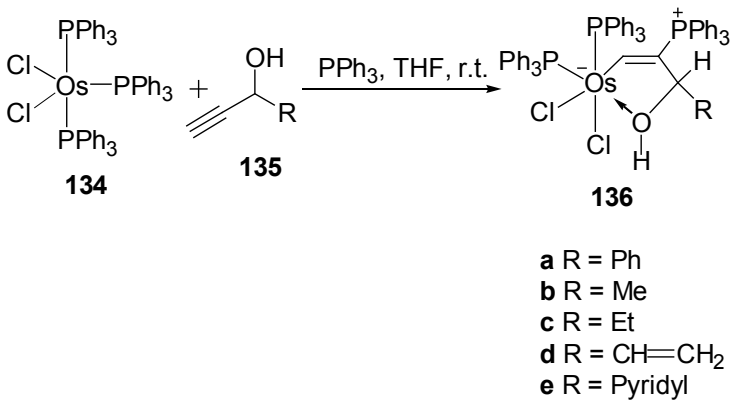

2009 年, 我们 ${ }^{[74]}$ 研究了化合物 136a 的脱羟基产物 烯基锇卡拜 137 与腈及其分子内 $\mathrm{C}-\mathrm{H}$ 活化反应. 137 可 与乙腈发生形式上的 $[4+2]$ 环加成反应生成锇吡啶盐 138 (Scheme 34), 化合物 138 是首例具有典型芳香性的 金属吡啶盐. 锇卡拜化合物 137 还可通过苯环的分子内 $\mathrm{C}-\mathrm{H}$ 活化选择性合成锇萗 139 及锇萗炔 $140^{[75]}$. 氮气氛 下, 137 在 DCE 中加热回流生成三氯桥连锇菜化合物 139, 氧气氛下反应则得到锇萗炔化合物 140.137 也可 
在固体状态下空气氛中加热转化成 140 . 此外, 氧气氛 下, 139 也能与酸及 $\mathrm{PPh}_{3}$ 反应高产率转化成 140 (Scheme 34). 该反应首次实现了金属苯与金属苯炔的转化.

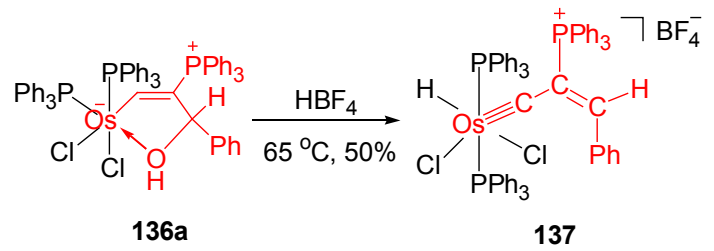

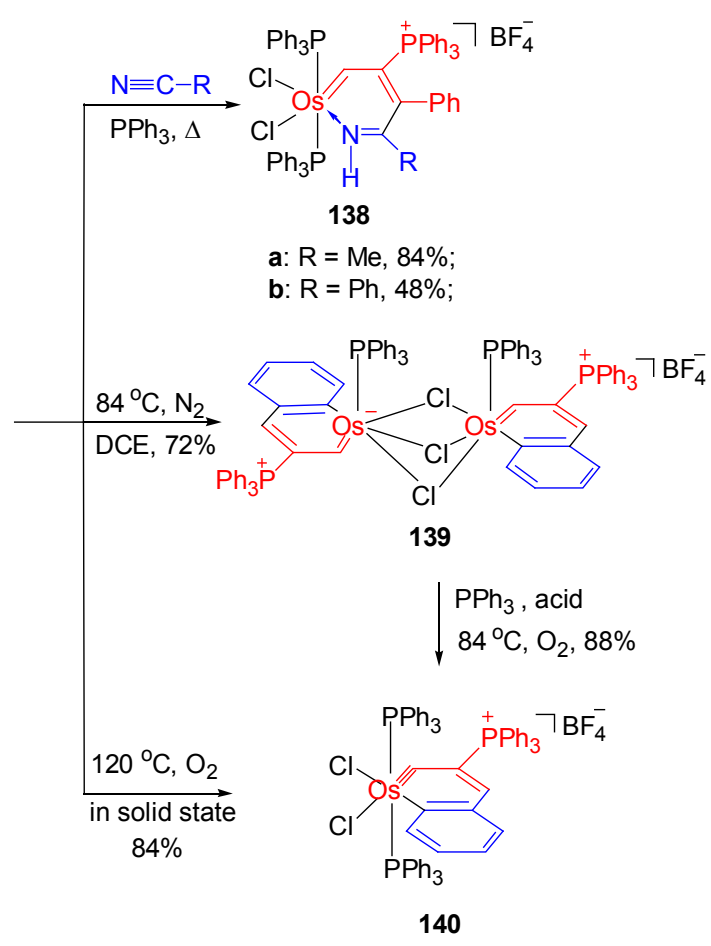

Scheme 34

化合物 136a 还可在酸和醇的作用下生成锇氢亚乙 烯基化合物 141. 化合物 141 可与 $\mathrm{HC} \equiv \mathrm{CCH}(\mathrm{OH}) \mathrm{Ph}$ 发 生形式上的 $[3+3]$ 环加成反应, 生成异锇苯 142a. 类似 的, 141 还能与 $\mathrm{HC} \equiv \mathrm{CCH}(\mathrm{OH}) \mathrm{CH}=\mathrm{CH}_{2}$ 和 $\mathrm{HC} \equiv$ $\mathrm{CCH}(\mathrm{OH}) \mathrm{CH}_{2} \mathrm{CH}_{3}$ 反应生成异锇苯 $142 \mathrm{~b}$ 和 $142 \mathrm{c}^{[76]}$ (Scheme 35). 另外, 锇亚乙烯基化合物 141 与 $\mathrm{HC} \equiv \mathrm{CCH}$ $(\mathrm{OEt})_{2}$ 则通过形式上的 $[3+3]$ 环加成反应生成锇苯炔 $143^{[77]}$.

最近, 我们还发现乙基取代的五元环化合物 $146 \mathrm{c}$ 可在酸作用下先形成乙烯基卡拜 144, 再进一步发生乙 基上的 $\mathrm{C}-\mathrm{H}$ 活化生成锇苯 146 (Scheme 36) ${ }^{[78]}$.

\section{4 总结与展望}

对于现代有机合成化学的研究而言, 如何全面地掌 控反应过程并将各个反应步骤进行巧妙组合, 从而设计 出环境友好的绿色合成实施计划是备受关注的主题. 而

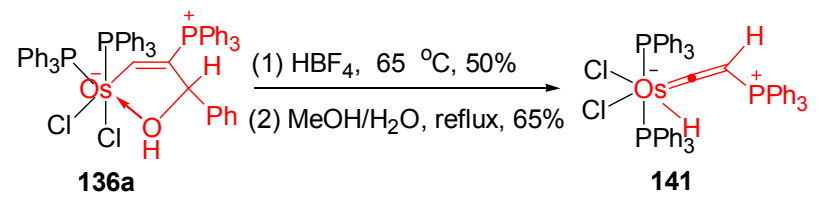

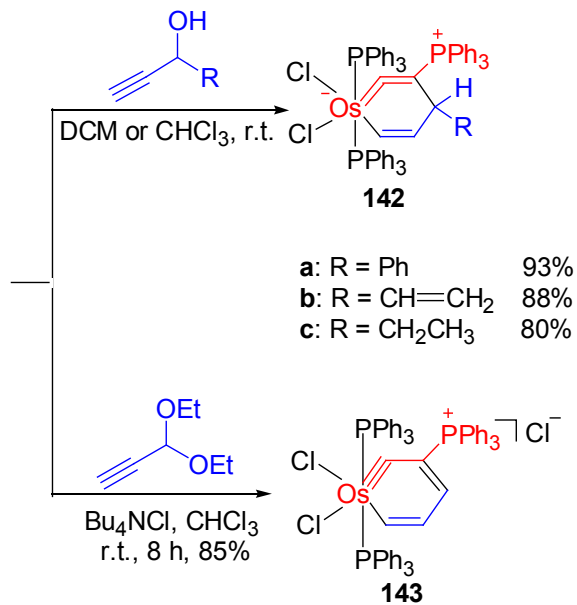

Scheme 35

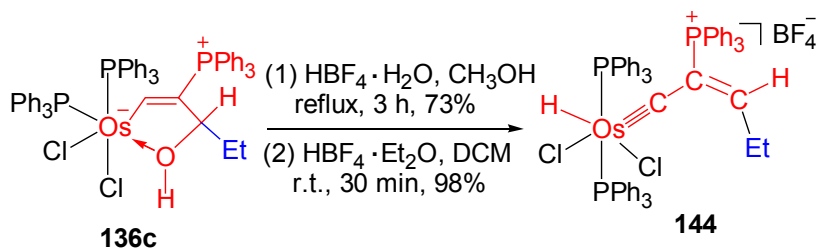

$136 \mathrm{c}$

(1) excess $\mathrm{RCN}, \mathrm{CHCl}_{3}$ (2) CO, r.t., $30 \mathrm{~min}$

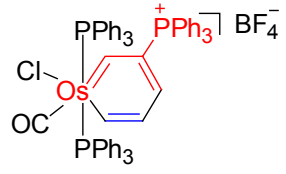

146<smiles>[R]OC(C)(C)c1ccccc1C#N</smiles>

Scheme 36

过渡金属杂小环化合物作为许多重要的金属参与的现 代有机合成反应以及金属促进的催化反应的活性中间 体，在有机合成、催化等相关领域都具有广阔的应用前 景, 成为当代化学前沿研究领域之一. 因此对过渡金属 杂小环的扩环反应深入的系统研究, 不仅有助于对反应 机理的探索, 而且能够挖掘合成方法学上的潜力.

由于过渡金属的多样性(不同金属、配体、氧化态、 几何构型等)、价键类型的复杂性以及成环模式的差异 性，使得过渡金属杂小环的扩环反应性具有较大差异. 金属杂五元环由于环张力相对较小, 比较稳定, 扩环反 
应较难发生. 而金属杂四元环的扩环反应研究相对更 多, 反应性也更加丰富. 此外，与前过渡系金属杂小环 相比，目前针对后过渡系金属杂小环化合物的扩环反应 的研究很少.

因此，总体而言，过渡金属杂小环的扩环反应(尤 其是后过渡系金属杂小环)具有广阔的拓展空间，对其 深入探索不仅有望合成新型金属有机化合物，还有望发 展全新的金属促进的高选择性催化反应，为高效、原子 经济性的绿色合成化学提供新方法.

\section{References}

[1] Selected reviews of metallacycles:

(a) Li, Z.; Zhao, B.; Xi, Z. Chemistry 2002, (2), 78 (in Chinese). (李志平, 赵炳筠, 席振峰, 化学通报, 2002, (2), 78.)

(b) Xi, Z.; Li, Z. Top. Organomet. Chem. 2004, 8, 27.

(c) Negishi, E. Dalton Trans. 2005, 827.

(d) Erker, G.; Kehr, G.; Fröhlich, R. Coord. Chem. Rev. 2006, 250, 36.

(e) Rosenthal, U.; Burlakov, V. V.; Bach, M. A.; Beweries, T. Chem. Soc. Rev. 2007, 719 .

(f) Suzuki, N.; Hashizume, D. Coord. Chem. Rev. 2010, 254, 1307.

(g) Chen, C.; Xi, C. Chin. Sci. Bull. 2010, 55, 3235.

(h) Beweries, T.; Haehnel, M.; Rosenthal, U. Catal. Sci. Technol. 2013, 3, 18 .

(i) Wang, Q.; Lin, C.; Xi, Z. Chin. J. Org. Chem. 2010, 30, 157 (in Chinese).

(王奇峰, 林辰, 席振峰, 有机化学, 2010, 30, 157.)

(j) Mao, K.; Fu, X.; Liu, D.; Li, S.; Liu, Y. Chin. J. Org. Chem. 2013, 33, 780 (in Chinese).

(毛可涁, 付晓平, 刘丹, 李石, 刘元红, 有机化学, 2013, 33, 780.)

[2] (a) Trnka, T. M.; Grubbs, R. H. Acc. Chem. Res. 2001, 34, 18.

(b) Vougioukalakis, G. C.; Grubbs, R. H. Chem. Rev. 2010, 110, 1746 .

[3] (a) Buchmeiser, M. R. Chem. Rev. 2000, 100, 1565.

(b) Choi, S.-K.; Gal, Y.-S.; Jin, S.-H.; Kim, H. K. Chem. Rev. 2000, 100, 1645.

[4] (a) Dewar, M. J. S. Bull. Soc. Chim. Fr. 1951, 18, C71.

(b) Chatt, J.; Duncanson, L. A. J. Chem. Soc. 1953, 2939.

[5] Frenking, G.; Fröhlich, N. Chem. Rev. 2000, 100, 717.

[6] Tsuchiya, K.; Kondo, H.; Nagashima H. Organometallics 2007, 26, 1044.

[7] Yamazaki, H.; Aoki, K.; Yamamoto, Y.; Wakatsuki, Y. J. Am. Chem. Soc. 1975, 97, 3546.

[8] Buchwald, S. L.; Lum, R. T.; Dewan, J. C. J. Am. Chem. Soc. 1986, $108,7441$.

[9] Buchwald, S. L.; Watson, B. T.; Huffman, J. C. J. Am. Chem. Soc. 1986, $108,7411$.

[10] Vaughan, G. A.; Sofield, C. D.; Hillhouse, G. L.; Rheingold, A. L. J. Am. Chem. Soc. 1989, 111, 5491.

[11] Buijink, J. K. F.; Kloetstra, K. R.; Meetsma, A.; Teuben, J. H. Organometallics 1996, 15, 2523.

[12] Beweries, T.; Fischer, C.; Peitz, S.; Burlakov, V. V.; Arndt, P.; Baumann, W.; Spannenberg, A.; Heller, D.; Rosenthal, U. J. Am. Chem. Soc. 2009, 131, 4463.

[13] Mansel, S.; Thomas, D.; Lefeber, C.; Heller, D.; Kempe, R.; Baumann, W.; Rosenthal, U. Organometallics 1997, 16, 2886.

[14] Zhang, S.; Zhang, W.-X.; Zhao, J.; Xi, Z. J. Am. Chem. Soc. 2010,
132,14042 .

[15] Lee, L. W. M.; Piers, W. E.; Parvez, M.; Rettig, S. J.; Young, V. G. Organometallics 1999, 18, 3904.

[16] (a) Schrock, R. R.; Pedersen, S. F.; Churchill, M. R.; Ziller, J. W. Organometallics 1984, 3, 1574.

(b) Zhu, J.; Jia, G.; Lin, Z. Organometallics 2006, 25, 1812.

(c) Mortreux A.; Coutelier, O. J. Mol. Catal. A: Chem. 2006, 254, 96.

[17] Loewe, C.; Shklover V.; Berke, H. Organometallics 1991, 10, 3396.

[18] (a) Padolik, L. L.; Gallucci, J. C.; Wojcicki, A. J. Am. Chem. Soc. 1993, 115, 9986

(b) Plantevin, V.; Gallucci, J. C.; Wojcicki, A. Inorg. Chim. Acto 1994, 222, 199.

(c) Plantevin, V.; Wojcicki, A. J. Organomet. Chem. 2004, 689, 2000.

[19] (a) Plantevin, V.; Wojcicki, A. J. Organomet. Chem. 2004, 689, 2013.

(b) Wu, H.-P.; Weakley, T. J. R.; Haley, M. M. Chem. Eur. J. 2005, 11,1191 .

[20] Recent reviews of metallabenzenes:

(a) Paneque, M.; Poveda, M. L.; Rendón, N. Eur. J. Inorg. Chem. 2011, 19.

(b) Jia, G. Coord. Chem. Rev. 2007, 251, 2167.

(c) Bleeke, J. R. Acc. Chem. Res. 2007, 40, 1035.

(d) Wright, L. J. Dalton Trans. 2006, 1821.

(e) Landorf, C. W.; Haley, M. M. Angew. Chem., Int. Ed. 2006, 45, 3914.

(f) Jia, G. Acc. Chem. Res. 2004, 37, 479.

(g) He, G.; Xia, H.; Jia, G. Chin. Sci. Bull. 2004, 49, 1543.

(h) Bleeke, J. R. Chem. Rev. 2001, 101, 1205.

[21] Clark, G. R.; Lu, G.-L.; Roper, W. R.; Wright L. J. Organometallics 2007, 26, 2167.

[22] Poon, K. C.; Liu, L.; Guo, T.; Li, J.; Sung, H. H. Y.; Williams, I. D.; Lin, Z.; Jia, G.. Angew. Chem., Int. Ed. 2010, 49, 2759.

[23] (a) Masuda, T.; Higashimura, T. Acc. Chem. Res. 1984, 17, 51. (b) Katz, T. J.; Sivavec, T. M. J. Am. Chem. Soc. 1985, 107, 737. (c) Fox, H. H.; Wolf, M. O.; O’Dell, R.; Lin, B. L.; Schrock, R. R.; Wrighton, M. S. J. Am. Chem. Soc. 1994, 116, 2827.

[24] (a) Katz, T. J. Angew. Chem., Int. Ed. 2005, 44, 3010.

(b) Diver, S. T. Coord. Chem. Rev. 2007, 251, 671.

(c) Mori, M. Materials 2010, 3, 2087.

(d) Li, J.; Lee, D. Eur. J. Org. Chem. 2011, 4269.

[25] Rubin, M.; Rubina, M.; Gevorgyan, V. Chem. Rev. 2007, 107, 3117.

[26] (a) Shono, T.; Kurashige, R.; Mukaiyama, R.; Tsubouchi, A.; Takeda, T. Chem. Eur. J. 2007, 13, 4074.

(b) O'Connor, J. M.; Baldridge, K. K.; Vélez, C. L.; Rheingold, A. L.; Moore, C. E. J. Am. Chem. Soc. 2013, 135, 8826.

[27] (a) Doxsee, K. M.; Mouser, J. K. M. Organometallics 1990, 9, 3012.

(b) Doxsee, K. M.; Mouser, J. K. M.; Farahi, J. B. Synlett 1992, 13.

[28] Doxsee, K. M.; Mouser, J. K. M. Tetrahedron Lett. 1991, 32, 1687.

[29] Meinhart, J. D.; Grubbs, R. H. Bull. Chem. Soc. Jpn. 1988, 61, 171.

[30] Heijden, H. V. D.; Hessen, B. Inorg. Chim. Acta 2003, 345, 27.

[31] (a) Stewart, I. C.; Douglas, C. J.; Grubbs, R. H. Org. Lett. 2008, 10, 441.

(b) Geny, A.; Leboeuf, D.; Rouquié, G.; Vollhardt, K. P. C.; Malacria, M.; Gandon, V.; Aubert, C. Chem. Eur. J. 2007, 13, 5408.

[32] Holland, R. L.; Bunker, K. D.; Chen, C. H.; DiPasquale, A. G.; Rheingold, A. L.; Baldridge, K. K.; O'Connor, J. M. J. Am. Chem. Soc. 2008, 130, 10093. 
[33] Meinhart, J. D.; Santarsiero, B. D.; Grubbs, R. H. J. Am. Chem. Soc. 1986, 108, 3318.

[34] Wakatsuki, Y.; Miya, S.-Y.; Yamazaki, H. J. Chem. Soc., Dalton. Trans. 1986, 1201.

[35] Werner, H.; Heinemann, A.; Windmüller, B.; Steinert, P. Chem. Ber. 1996, 129, 903.

[36] Beckhaus, R.; Sang, J.; Wagner, T.; Ganter, B. Organometallics 1996, 15, 1176.

[37] Holland, R. L.; O'Connor, J. M. Organometallics 2009, 28, 394.

[38] Doxsee, K. M.; Farahi, J. B. J. Am. Chem. Soc. 1988, 110, 7239.

[39] Motz, P. L.; Alexander, J. J.; Ho, D. M. Organometallics 1989, 8, 2589.

[40] Stack, J. G.; Simpson, R. D.; Hollander, F. J.; Bergman, R. G.; Heathcock, C. H. J. Am. Chem. Soc. 1990, 112, 2716.

[41] Hartwig, J. F.; Bergman, R. G. Andersen R. A. Organometallics 1991, 10, 3344.

[42] Ajulu, F. A.; Carmichael, D.; Hitchcock, P. B.; Mathey, F.; Meidine, M. F.; Nixon, J. F.; Ricard L.; Riley, M. L. J. Chem. Soc., Chem. Commun. 1992, 750.

[43] Tanabe, M.; Horie, M. Osakada, K. Organometallics 2003, 22, 373.

[44] Cristóbal, C.; Hernández, Y. A.; López-Serrano, J.; Paneque, M.; Petronilho, A.; Poveda, M. L.; Salazar, V.; Vattier, F.; Álvarez, E.; Maya, C.; Carmona, E. Chem. Eur. J. 2013, 19, 4003.

[45] (a) Takahashi, T.; Xi, Z.; Obora, Y.; Suzuki, N. J. Am. Chem. Soc. 1995, 117, 2665.

(b) Xi, Z.; Fischer, R.; Hara, R.; Sun, W.-H.; Obora, Y.; Suzuki, N.; Nakajima, K.; Takahashi, T. J. Am. Chem. Soc. 1997, 119, 12842.

[46] (a) Sun, X.; Wang, C.; Li, Z.; Zhang, S.; Xi, Z. J. Am. Chem. Soc. 2004, 126, 7172 .

(b) Zhang, W.-X.; Zhang, S.; Sun, X.; Nishiura, M.; Hou, Z.; Xi, Z. Angew. Chem., Int. Ed. 2009, 48, 7227.

(c) Zhang, S.; Sun, X.; Zhang, W.-X.; Xi, Z. Chem. Eur. J. 2009, 15, 12608.

(d) Zhang, S.; Zhang, W.-X.; Xi, Z. Chem. Eur. J. 2010, 16, 8419.

(e) Zhang, S.; Zhao, J.; Zhang, W.-X.; Xi, Z. Org. Lett. 2011, 13, 1626.

(f) Zhang, S.; Zhang, W.-X.; Zhao, J.; Xi, Z. Chem. Eur. J. 2011, 17,2442 .

(g) Zhao, J.; Zhang, S.; Zhang, W.-X.; Xi, Z. Organometallics 2011, 30, 3464.

(h) Zhao, J.; Zhang, S.; Zhang, W.-X.; Xi, Z. Organometallics 2012, 31, 8370 .

(i) Zhao, J.; Zhang, S.; Zhang, W.-X.; Xi, Z. Organometallics 2014, 33,8 .

[47] (a) Yu, T.; Deng, L.; Zhao, C.; Li, Z.; Xi, Z. Tetrahedron Lett. 2003, 44, 677.

(b) Liu, J.; Zhang, S.; Zhang, W.-X.; Xi, Z. Organometallics 2009, $28,413$.

[48] Yu, T.; Sun, X.; Wang, C.; Deng, L.; Xi, Z. Chem. Eur. J. 2005, 11, 1895.

[49] Zhang, W.-X.; Zhang, S.; Xi, Z. Acc. Chem. Res. 2011, 44, 541.

[50] Zhao, J.; Zhang, S.; Zhang, W.-X.; Xi, Z. Coord. Chem. Rev. 2014, $270,2$.

[51] (a) Xi, Z.; Li, Z. Top. Organomet. Chem. 2004, 8, 27.

(b) Xi, Z. Top. Catal. 2005, 35, 63.

(c) Takahashi, T.; Kuzuba, Y.; Kong, F.; Nakajima, K.; Xi, Z. J. Am. Chem. Soc. 2005, 127, 17188.

(d) Leng, L.; Xi, C.; Shi, Y.; Guo, B. Synlett 2003, 183.

(e) Chen, C.; Xi, C.; Lai, C.; Wang, R.; Hong, X. Eur. J. Org. Chem. 2004, 647.

(f) Leng, L.; Xi, C.; Chen, C.; Lai, C. Tetrahedron Lett. 2004, 45, 595. (g) Chen, C.; Xi, C.; Liu, Y.; Hong, X. J. Org. Chem. 2006, 71, 5373.

(h) Chen, C.; Yan, X.; Xi, C. Synth. Commun. 2010, 40, 570.

(i) Zhou, Y.; Yan, X.; Chen, C.; Xi, C. Organometallics 2013, 32, 6182.

[52] (a) Shi, L.; Zhou, L.; Kanno, K.-I.; Takahashi, T. J. Heterocycl. Chem. 2011, 48, 517.

(b) Ojima, I.; Tzamarioudaki, M.; Li, Z.; Donovan, R. J. Chem. Rev. 1996, 96, 635.

(c) Liu, J.; Zhang, W.-X.; Guo, X.; Hou, Z.; Xi, Z. Organometallics 2007, 26, 6812 .

[53] Xi, Z.; Sato, K.; Gao, Y.; Lu, J.; Takahashi, T. J. Am. Chem. Soc. 2003, 125, 9568 .

[54] (a) Xi, Z.; Fan, H.; Mito, S.; Takahashi, T. J. Organomet. Chem. 2003, 682, 108.

(b) Lu, J.; Mao, G.; Zhang, W.; Xi, Z. Chem. Commun. 2005, 4848.

(c) Hu, Q.; Lu, J.; Wang, C.; Wang, C.; Xi, Z. Tetrahedron 2007, $63,6614$.

[55] (a) Xi, Z.; Li, P. Angew. Chem., Int. Ed. 2000, 39, 2950.

(b) Zhao, C.; Li, P.; Cao, X.; Xi, Z. Chem. Eur. J. 2002, 8, 4292.

(c) Xi, Z.; Guo, R.; Mito, S.; Yan, H.; Kanno, K.; Nakajima, K.; Takahashi, T. J. Org. Chem. 2003, 68, 1252.

(d) Chen, C.; Xi, C.; Jiang, Y.; Hong, X. J. Am. Chem. Soc. 2005, 127,8024 .

(e) Chen, C.; Xi, C.; Ai, Z.; Hong, X. Org. Lett. 2006, 8, 4055.

[56] Xi, Z.; Huo, S.; Noguchi, Y.; Takahashi, T. Chem. Lett. 2000, 218.

[57] (a) Chin, C. S.; Kim, M.; Lee, H.; Noh, S.; Ok, K. M. Organometallics 2002, 21, 4785.

(b) Chin, C. S.; Lee, H. Chem. Eur. J. 2004, 10, 4518.

[58] Elliott, G. P.; Roper, W. R.; Waters, J. M. J. Chem. Soc., Chem. Commun. 1982, 811.

[59] Clark, G. R.; Johns, P. M.; Roper, W. R.; Wright, J. L. Organometallics 2008, 27, 451.

[60] Dalebrook, A. F.; Wright, L. J. Organometallics 2009, 28, 5536.

[61] Clark, G. R.; Johns, P. M.; Roper, W. R. Sohnel, T.; Wright, L. J. Organometallics 2011, 30, 129.

[62] (a) Zhou, S.; Liu, D.; Liu, Y. Organometallics 2004, 23, 5900.

[63] Lin, Y.; Gong, L.; Xu, H.; He, X.; Wen, T. B.; Xia, H. Organometallics 2009, 28, 1524.

[64] (a) Fu, X.; Chen, J.; Li, G.; Liu, Y. Angew. Chem., Int. Ed. 2009, 48, 5500 .

(b) Fu, X.; Liu, Y.; Li, Y. Organometallics 2010, 29, 3012.

(c) Fu, X.; Yu, S.; Fan, G.; Liu Y.; Li, Y. Organometallics 2012, 31, 531.

(d) Yu, S.; You, X.; Liu Y. Chem. Eur. J. 2012, 18, 13936.

(e) You, X.; Yu, S.; Liu Y. Organometallics 2013, 32, 5273.

[65] Pellny, P.-M.; Kirchbauer, F. G.; Burlakov, V. V.; Baumann, W.; Spannenberg, A.; Rosenthal, U. J. Am. Chem. Soc. 1999, 121, 8313.

[66] Bender, G.; Kehr, G.; Frohlich, R.; Petersen, J. L.; Erker, G. Chem. Sci. 2012, 3, 3534.

[67] Wang, T.; Zhu, J.; Han, F.; Zhou, C.; Chen, H.; Zhang, H.; Xia, H. Angew. Chem., Int. Ed. 2013, 52, 13361.

[68] (a) Liu, Y.; Gao, H.; Zhou, S. Angew. Chem., Int. Ed. 2006, 45, 4163 .

(b) Zhou, Y.; Chen, J.; Zhao, C.; Wang, E.; Liu, Y.; Li, Y. J. Org. Chem. 2009, 74, 5326.

[69] (a) Coperet, C.; Negishi, E.; Xi, Z.; Takahashi, T. Tetrahedron Lett. 1994, 35, 695.

(b) Li, P.; Xi, Z.; Takahashi, T. Chin. J. Chem. 2001, 19, 45.

(c) Zhao, C.; Yan, J.; Xi, Z. J. Org. Chem. 2003, 68, 4355.

(d) Zhao, C.; Lu, J.; Yan, J.; Xi, Z. Tetrahedron Lett. 2003, 44, 6895 . 
(e) Zhao, C.; Lu, J. Li, Z.; Xi, Z. Tetrahedron 2004, 60, 1417.

[70] Gong, L.; Wu, L.; Lin, Y.; Zhang, H.; Yang, F.; Wen, T. B.; Xia, H. Dalton Trans. 2007, 4122.

[71] (a) Mao, K.; Fan, G.; Liu, Y.; Li, S.; Xu, Y.; Dan, L. Beilstein J. Org. Chem. 2013, 9, 621.

(b) Chen, J.; Liu, Y. Organometallics 2010, 29, 505.

[72] (a) Liu, B.; Zhao, Q.; Wang, H.; Zeng, B.; Cao, X.; Xia, H. Sci. China Chem. 2013, 56, 1105.

(b) Zhang, C.; Zhang, H.; Wei, A.; He, X.; Xia, H. Acta Chim. Sinica 2013, 71, 1373 (in Chinese).

(张春红, 张弘, 魏爱琳, 何旭敏, 夏海平, 化学学报, 2013, 71, 1373.)

[73] Zhang, C.; Zhang, H.; Zhang, L.; Wen, T. B.; He, X.; Xia, H. Organometallics 2013, 32, 3738 .

[74] (a) Liu, B.; Wang, H.; Xie, H.; Zeng, B.; Chen, J.; Tao, J.; Wen, T.
B.; Cao, Z.; Xia, H. Angew. Chem., Int. Ed. 2009, 48, 5430.

(b) Liu, B.; Zhao, Q.; Wang, H.; Chen, J.; Cao, X.; Cao, Z.; Xia, H. Chin. J. Chem. 2012, 30, 2158.

[75] Liu, B.; Xie, H. J; Wang, H.; Wu, L.; Zhao, Q.; Chen, J.; Wen, T. B.; Cao, Z.; Xia, H. Angew. Chem., Int. Ed. 2009, 48, 5461.

[76] (a) Zhao, Q.; Gong, L.; Xu, C.; Zhu, J.; He, X.; Xia, H. Angew. Chem., Int. Ed. 2011, 50, 1354.

(b) Zhu, C.; Cao, X.; Xia, H. Chin. J. Org. Chem. 2013, 33, 657.

(c) Zhao, Q.; Cao, X.-Y.; Wen, T. B.; Xia, H. Chem. Asian J. 2013, $8,269$.

[77] Zhao, Q.; Zhu, J.; Huang, Z.; Cao, X.-Y.; Xia, H. Chem. Eur. J. 2012, 18, 11597.

[78] Chen, J; Zhang, C.; Xie, T.; Wen, T. B.; Zhang, H.; Xia, H. Organometallics 2013, 32, 3993. 